\title{
Removal of Dyes Using Graphene Oxide (GO) Mixed Matrix Membranes
}

\author{
Rana J. Kadhim ${ }^{1}$, Faris H. Al-Ani ${ }^{1}$, Muayad Al-shaeli ${ }^{2}$, Qusay F. Alsalhy ${ }^{3, * \mathbb{D}}$ and \\ Alberto Figoli ${ }^{4}$ (1) \\ 1 Civil Engineering Department, University of Technology, Alsinaa Street 52, Baghdad 10066, Iraq; \\ rana1979.kadhim@gmail.com (R.J.K.); 40027@uotechnology.edu.iq (F.H.A.-A.) \\ 2 Department of Chemical Engineering, Monash University, Clayton, VIC 3800, Australia; \\ muayad.al-shaeli@monash.edu \\ 3 Membrane Technology Research Unit, Chemical Engineering Department, University of Technology, \\ Alsinaa Street 52, Baghdad 10066, Iraq \\ 4 Institute on Membrane Technology, National Research Council (ITM-CNR), 87030 Rende, Italy; \\ a.figoli@itm.cnr.it \\ * Correspondence: qusay_alsalhy@yahoo.com or 80006@uotechnology.edu.iq; Tel.: +964-790-173-0181
}

Received: 23 October 2020; Accepted: 23 November 2020; Published: 25 November 2020

\begin{abstract}
The application of membrane technology to remove pollutant dyes in industrial wastewater is a significant development today. The modification of membranes to improve their properties has been shown to improve the permeation flux and removal efficiency of the membrane. Therefore, in this work, graphene oxide nanoparticles (GO-NPs) were used to modify the polyethersulfone (PES) membrane and prepare mixed matrix membranes (MMMs). This research is dedicated to using two types of very toxic dyes (Acid Black and Rose Bengal) to study the effect of GO on PES performance. The performance and antifouling properties of the new modified membrane were studied using the following: FTIR, SEM, AFM, water permeation flux, dye removal and fouling, and by investigating the influence of GO-NPs on the structure. After adding $0.5 \mathrm{wt} \%$ of GO, the contact angle was the lowest $\left(39.21^{\circ}\right)$ and the permeable flux of the membrane was the highest. The performance of the ultrafiltration (UF) membrane displayed a rejection rate higher than $99 \%$ for both dyes. The membranes showed the highest antifouling property at a GO concentration of $0.5 \mathrm{wt} \%$. The long-term operation of the membrane fabricated from $0.5 \mathrm{wt} \%$ GO using two dyes improved greatly over $26 \mathrm{~d}$ from $14 \mathrm{~d}$ for the control membrane, therefore higher flux can be preserved.
\end{abstract}

Keywords: PES membrane; graphene oxide; hydrophilicity; membrane formation; wastewater treatment; polyvinylpyrrolidone

\section{Introduction}

As a result of the huge discharge of industrial wastewater and the shortage of water resources, the accumulation of waste and contaminants in water is a global environmental problem leading to unsafe water for human use. Additionally, the global demand for fresh water has increased significantly due to population growth, increasing urbanization, industrialization, and expanding economies. Therefore, sustainable and clean technologies are urgently required to solve this global challenge [1].

Due to the high salinity and toxicity of azo dyes, they are one of the most dangerous pollutants in wastewater [2,3]. They play a key role in coloring cellulose fibers (such as cotton), and the use of reactive dyes can cause serious environmental problems [4]. Due to the complexity of dye molecules and their resistance to aerobic digestion, oxidants, light, and heat, wastewater from the textile industry is difficult to treat [5]. The main industries that release dyes into the environment are the textile industry, which creates 
over half (54\%) of the existing dye wastewater worldwide; dyeing industry (21\%); pulp and paper industry $(10 \%)$; paint and leather industry ( $8 \%)$; and dye manufacturing industry $(7 \%)$ [6]. Therefore, it is critical to use clean, economical, and effective treatment methods, such as membrane separation, to treat dyes.

Membrane separation technologies are considered to be the best solution to overcome water scarcity by providing high-quality fresh water to many people. These technologies boast outstanding properties, such as low operating costs, high separation efficiency, reliability, simplicity, and being more environmentally friendly than conventional water treatment technologies. Therefore, these methods have been applied in many industries, including waste treatment [7], pharmaceutical synthesis [8], food manufacturing, dyestuff industry [9], brackish water treatment, and desalination [10].

As a part of membrane separation technology, the use of an ultrafiltration (UF) membrane is a clean, efficient, and attractive technology, which effectively removes suspended particles, bacteria, and organic compounds. Polymeric materials used to fabricate ultrafiltration membranes include polyethersulfone (PES), polyvinylidene fluoride (PVDF), polyacrylonitrile (PAN), and bromomethylated polyphenylene oxide (BPPO). Although these polymer materials are commercially available, their low permeation flux and fouling issues limit their applicability in industry. Researchers have devised many methods to improve the performance of polymeric membranes, including the use of polymer blends [11]; various additives, including water-soluble materials [12], nanoparticles, and nanomaterials [13-19]; and free radical graft copolymerization (chemical modification) [20]. Among the several polymeric materials used to manufacture ultrafiltration membranes, significant interest lies with polyethersulfone membranes (PES) due to the beneficial properties of PES, including excellent chemical and thermal stability, remarkable oxidation resistance, outstanding robustness and tolerance of solvents, and enhanced mechanical properties. One of the main obstacles to PES membrane use is fouling, which reduces the membrane flux either permanently or temporarily, thus affecting the lifetime of the membrane. In fact, a PES membrane is influenced by fouling problems because of the interactions between the surface charges of the PES membrane and the foulants, which may be organic, inorganic, or biological forms. Therefore, the hydrophilic modification of PES is a crucial task, which can provide higher separation efficiency and higher antifouling performance to durable UF membranes for high-quality water treatment.

As mentioned above, many research studies have used hydrophilic nanomaterials and nanoparticles as nanofillers blended with polymer materials to enhance the hydrophilicity and antifouling performance of the UF membranes. However, within the past seven years, many studies have focused on using graphene oxide nanoparticles $\left(\mathrm{GO}-\mathrm{NP}_{\mathrm{S}}\right)$ as a potential for dye removal due to its exceptional conjugated two-dimensional structure (2D), which has demonstrated a higher adsorption capacity for various dye molecules through $\pi-\pi$ stacking interactions [21-26]. Moreover, the negative charges in the GO sheets that result from various oxygen-rich functional groups (i.e., carboxyl (-COOH), carbonyl, epoxy (C-O-C), and hydroxyl groups $(-\mathrm{OH})$ ) allow for additional strong electrostatic interactions with cationic dye molecules [26-28]. The incorporation of GO sheets into the polymer appears to make it highly attractive for multiple purposes due to its remarkable properties. These include a two-dimensional structure, the ability to promote negative surface charges, outstanding electron transport, high surface area, innocuity, and remarkable chemical stabilities. GO can also change the roughness and mechanical properties of membranes and the effects of membrane fouling. It can increase water permeation flux and surface hydrophilicity, improve mechanical strength, reduce both organic and biofouling propensity, and efficiently separate dye [29].

Among the GO studies in membrane technology, Zinadini et al. [30] investigated the impact of blending a GO nanoplate on PES/ polyvinylpyrrolidone (PVP) nanofiltration membranes for dye removal and powder milk filtration. GO-modified PES membranes exhibited a higher dye removal capacity than pristine PES-UF membranes. Wang et al. [31] found that a GO nanosheet blended into a PVDF polymer matrix improved the membrane hydrophilicity, water permeation flux, and antifouling performance of the membrane. Other researchers used GO as a filler in different separation applications to modify polymeric membranes (e.g., PES, polysulfone (PSF), and PVDF membranes) [32-40] and 
make mixed matrix membranes (MMMs). They proved that GO is a great candidate to enhance the membrane water flux and keep/maintain the \% rejection at a high level.

The aim of this work is to prepare mixed matrix membranes (MMMs) with higher capabilities to remove very toxic dyes from wastewater. Modifying a PES membrane for the removal of very toxic dyes such as Acid Black-210 and Rose Bengal, which are dissolved in wastewater of the leather tanning and textile industries, respectively, has not been investigated in detail. In fact, wastewater of the leather tanning and textile industries is a complex mixture and unmodified membranes cannot treat it and remove such dyes effectively. Therefore, a favorable technique for modifying a PES membrane with GO for removal of Acid Black-210 and Rose Bengal is necessary and workable. Moreover, the effect of embedded GO in the polymer solution on the cross-sectional structure of the membrane was not presented previously in detail. Therefore, in the current research study, GO particles were added to PES UF casting solutions for the removal of dyes from wastewater of leather tanning and textile industries. The effect of GO on the cross-sectional morphology and hydrophilicity was extensively investigated. The efficiency of the PES membranes was measured in terms of the permeation flux and the anionic dye removal efficiency of Acid Black-210 and Rose Bengal. The synthesized GO and the prepared membrane were characterized by Fourier transform infrared (FTIR) spectroscopy, scanning electron microscopy (SEM), atomic force microscopy (AFM), and water contact angle (CA) measurement.

\section{Experimental Work}

\subsection{Chemicals}

All the chemicals used in the experimental work were of a reagent grade. Polyethersulfone polymer (PES; Ultrason E6020P, $51 \mathrm{kDa}$ ) was purchased from Solvay Specialty Polymers, Belgium. Polyvinylpyrrolidone (PVP; $25 \mathrm{kDa}$ ) was provided by Mowiol, Germany. Dimethyl sulfoxide (DMSO; $\left.\left(\mathrm{CH}_{3}\right)_{2} \mathrm{SO}\right)$ with a density of $1.1 \mathrm{~g} / \mathrm{mL}$ and $\mathrm{Mwt}=78.13 \mathrm{~g} / \mathrm{mol}$ was utilized as a polymer solvent and obtained from Sigma-Aldrich (St. Louis, MO, USA). Sulfuric acid $\left(\mathrm{H}_{2} \mathrm{SO}_{4} ; 98 \%\right)$ was provided from Central Drug House, Delhi, India. Potassium persulfate $\left(\mathrm{K}_{2} \mathrm{~S}_{2} \mathrm{O}_{8}\right)$ was ordered from RIEDEL-DE HAEN AG, Seelze-Hannover. Phosphorus pentoxide $\left(\mathrm{P}_{2} \mathrm{O}_{5}\right.$; white powder, $\left.\mathrm{Mwt}=141.96\right)$ was purchased from Scharlau, Australia. Graphene platelet powder (6-8 nm pore size) was ordered from Skyspring Nanomaterials, Inc. (Houston, TX, USA). Acid Black 210 dye $\left(\mathrm{C}_{34} \mathrm{H}_{25} \mathrm{~N}_{11} \mathrm{O}_{11} \mathrm{~S}_{3} ; \mathrm{Mw}=938.017 \mathrm{~g} / \mathrm{mol}\right)$ was procured from Leeds, United Kingdom. Rose Bengal dye $\left(\mathrm{C}_{20} \mathrm{H}_{2} \mathrm{CL}_{4} \mathrm{~L}_{4} \mathrm{Na}_{2} \mathrm{O}_{5} ; \mathrm{Mw}=1017 \mathrm{~g} / \mathrm{mol}\right.$, $\lambda_{\max }=520 \mathrm{~nm}$ ) was purchased from HiMedia Laboratories, India.

\subsection{Preparation of the Graphene Oxide (GO)}

Graphene oxide (GO) was synthesized using a modified Hummers method. First, a solution was prepared that consisted of $120 \mathrm{~cm}^{3}$ concentrated sulfuric acid $\left(\mathrm{H}_{2} \mathrm{SO}_{4}\right), 15.6 \mathrm{~g}$ potassium persulfate $\left(\mathrm{K}_{2} \mathrm{~S}_{2} \mathrm{O}_{8}\right)$, and $16.8 \mathrm{~g}$ phosphorus pentoxide $\left(\mathrm{P}_{2} \mathrm{O}_{5}\right)$. Then, $30 \mathrm{~g}$ of graphite was added to the prepared solution and refluxed in a condenser at $75-80{ }^{\circ} \mathrm{C}$ for $4 \mathrm{~h}$. Next, the solution was allowed to cool at ambient temperature. After that, the solution was filtered and washed successively with distilled water until the $\mathrm{pH}$ became neutral (i.e., $\mathrm{pH}=7$ ). The product was dried in an oven at $60^{\circ} \mathrm{C}$ for $48 \mathrm{~h}$ [18].

\subsection{Preparation of the Membrane}

To further prepare the membrane, dried PES powder (21 and $1 \mathrm{wt} \%$ PVP) was dissolved in dimethyl sulfoxide (DMSO) solvent and stirred using a magnetic stirrer for $24 \mathrm{~h}$ at ambient temperature. PVP was used as the pore-forming additive. GO particles at different concentrations from 0.1 to $2 \mathrm{wt} \%$ were added to the homogeneous PES-PVP solution and stirred for more than $3 \mathrm{~h}$. Then, the PES-PVP-GO solutions were kept in an ultrasonic bath (operated at 50-100 watts per gallon) for $30 \mathrm{~min}$ to avoid the agglomeration of the GO-NPs in the final casting solution. Then, the casting solution was poured on a precleaned glass plate, and a self-made casting knife was used to cast at room temperature. The phase inversion was carried out by soaking the casting solution in a water 
coagulation bath for $24 \mathrm{~h}$. The membrane was then taken from the bath and rinsed thoroughly with double deionized water (DDI) and stored in fresh DDI before use. Next, the membrane was placed in another water bath mixed with glycerin to prevent the membrane structure from collapsing. Table 1 lists the composition of the casting solution for all of the membranes.

Table 1. The compositions of the casting solution.

\begin{tabular}{ccccc}
\hline $\begin{array}{c}\text { Membrane } \\
\text { Label }\end{array}$ & $\begin{array}{c}\text { PES Content } \\
\text { (wt.\%) }\end{array}$ & $\begin{array}{c}\text { PVP Content } \\
\text { (wt.\%) }\end{array}$ & $\begin{array}{c}\text { DMSO } \\
\text { Content (wt.\%) }\end{array}$ & $\begin{array}{c}\text { GO Content } \\
\text { (wt.\%) }\end{array}$ \\
\hline 1 & 21 & 1 & 78 & 0 \\
2 & 21 & 1 & 78 & 0.1 \\
3 & 21 & 1 & 78 & 0.2 \\
4 & 21 & 1 & 78 & 0.3 \\
5 & 21 & 1 & 78 & 0.5 \\
6 & 21 & 1 & 78 & 1.5 \\
7 & 21 & 1 & 78 & 2 \\
\hline
\end{tabular}

\subsection{Membrane Characteristics}

\subsubsection{Fourier Transform Infrared (FTIR) Spectroscopy}

A Fourier transform infrared-attenuated total reflection (FTIR-ATR) spectrometer (PerkinElmer, Australia) was used to check the chemical structure of the membrane. It was characterized by FTIR with a resolution of $4 \mathrm{~cm}^{-1}$ in the range of $500-4000 \mathrm{~cm}^{-1}$, and the average value was taken over 64 scans.

\subsubsection{Scanning Electron Microscopy (SEM)}

A scanning electron microscope (SEM) measurement (TESCAN VEGA3 SB instrument, EO Elektronen-Optik-Service $\mathrm{GmbH}$, Germany) was used to examine the top membrane surface and cross-sectional morphology of the control membrane and the modified PES membrane at an accelerating voltage of $30 \mathrm{KV}$. Membrane samples were prepared by drying the membrane at room temperature and sputtering the coating with a $0.5-\mathrm{nm}$ thickness of Pd metal. For cross-sectional images, the membrane was broken in liquid nitrogen to retain the membrane structure and then, inspected using SEM equipment. The cross-section and outer surface of the membrane were scanned at several magnifications. The PES/GO membrane was analyzed using SEM and an energy dispersive $X$-ray spectrometer (SEM-EDX). After the SEM images were taken, analysis of the GO-NPs by EDX was conducted.

\subsubsection{Atomic Force Microscopy (AFM)}

A scanning probe microscope (SPM AA300 Angstrom Advanced Inc., AFM, USA) was used to characterize the surface morphology and roughness of the prepared membrane. A membrane sample was cut about $1 \mathrm{~cm}^{2}$ and fixed on the holder, where an $8.8 \times 8.8 \mu \mathrm{m}$ area was scanned. The surface roughness parameter is reflected as the average roughness $S_{a}$, the root mean square of the $Z$ data $S_{q}$, and the average difference between the highest peak and the lowest valley $S_{z}$.

\subsubsection{Contact Angle}

The hydrophilicity of the membrane was measured using a contact angle goniometer by the sessile drop technique (110-O4W CAM, Tainan, Taiwan). To achieve optimal accuracy, at least five contact angle measurements at different locations for each membrane sample were recorded, and an average was calculated. 


\subsubsection{Porosity}

Using the gravimetric method, the porosity of the membranes was determined, as defined in the following equation [41]:

$$
\varepsilon=\frac{\mathrm{W} 1-\mathrm{W} 2}{\mathrm{~A} * \mathrm{~T} * \rho} .
$$

where $\varepsilon$ is the porosity (\%); W1 is the weight of the wet membrane (g); W2 is the weight of the dry sample (g); A is the membrane effective area $\left(\mathrm{cm}^{2}\right)$; T is the membrane thickness $(\mu \mathrm{m})$; and $\rho$ is the water density $\left(0.998 \mathrm{~g} / \mathrm{cm}^{3}\right.$ at $\left.25^{\circ} \mathrm{C}\right)$. The membrane samples of pristine and modified PES membranes were soaked in distilled water for $24 \mathrm{~h}$ at room temperature. Then, any water was wiped off the membranes, and each membrane was weighed [41].

\subsubsection{Pore Radius}

The mean radius of the membrane pore (rm) was estimated by Equation (2) (i.e., the GueroutElford-Ferry equation) [39].

$$
\mathrm{r}_{\mathrm{m}}=\sqrt{\frac{(2.9-1.75 \varepsilon) 8 \eta 1 \mathrm{Q}}{\varepsilon \times \mathrm{A} \times \Delta \mathrm{P}}}
$$

where $r_{m}$ is the mean pore radius $(\mathrm{nm}), \eta$ is the viscosity of the water $\left(8.9 \times 10^{-4} \mathrm{~Pa} \mathrm{~s}\right), 1$ is the thickness of the membrane $(\mathrm{m}), \mathrm{Q}$ is the collected volume of the permeate per unit time $\left(\mathrm{m}^{3} / \mathrm{s}\right), \mathrm{A}$ is the membrane surface area $\left(\mathrm{m}^{2}\right)$, and $\Delta \mathrm{P}$ is the transmembrane pressure $(\mathrm{Pa})$.

\subsubsection{Mechanical Properties (Tensile Strength)}

A Zwick/Roell device (Germany) was used for the tensile measurement of the membrane at room temperature. The membrane sample was cut into $10 \times 100 \mathrm{~mm}$ shapes. The three samples were checked to ensure they had a loading rate of $5 \mathrm{~mm} / \mathrm{min}$ for breaking strength, and the average of the tensile strength was calculated to increase the accuracy. The tensile strength at the fracture was calculated by dividing the force at the fracture $(\mathrm{N})$ by the cross-sectional area of the sample $\left(\mathrm{m}^{2}\right)$ [42].

\subsubsection{Zeta Potential Test}

A zeta potential analyzer (Zetasizer 3000HS, Malvern Co., UK) was used to determine the zeta potential of the organic dye within a wide $\mathrm{pH}$ range. Initially, the dye was dried in an oven at $50^{\circ} \mathrm{C}$ to remove water, after which it was dissolved in deionized water. Sodium hydroxide and hydrochloric acid were used to adjust the $\mathrm{pH}$ of the dye solution to be in the range from 3 to 10. At least three rounds were performed for each sample, and the average value was recorded.

\subsubsection{Membrane Filtration Experiments}

The pure water flux (PWF) of the pristine and PES-PVP-GO membranes was measured using the cross-flow filtration process shown in Figure 1. The effective membrane filtration area was $16 \mathrm{~cm}^{2}$. Initially, each membrane sample was pre-compacted for at least $90 \mathrm{~min}$ until the flux stabilized at 3 bar. Then, filtration tests were conducted at a steady pressure of 3 bar and temperature of $25 \pm 1{ }^{\circ} \mathrm{C}$.

The rejection test was performed with four aqueous solutions (i.e., 10, 50, 80, and $100 \mathrm{ppm}$ ) of Acid Black-210 and Rose Bengal dyes. The $\mathrm{pH}$ value of each of the two dye solutions naturally was equal to 5. To calculate the separation efficiency of the membranes, the concentration of dyes in the permeate solution was determined using a spectrophotometer (UV 1100) at $\lambda_{\max }$ of 460 and $520 \mathrm{~nm}$. The pure water flux, $J\left(\mathrm{~L} / \mathrm{m}^{2} . \mathrm{h}\right)$ and dye separation efficiency $R(\%)$ were determined according to Equations (3) and (4), respectively.

$$
J_{1}=\frac{V}{A * t}
$$


where $J_{1}$ is the pure water permeation flux of the membrane $\left(\mathrm{L} \mathrm{m}^{-2} \mathrm{~h}^{-1}\right) ; V$ is the volume of the permeate collected (L); $t$ is the time the permeate was collected $(\mathrm{h})$; and $A$ is the membrane surface area $\left(\mathrm{m}^{2}\right)$.

$$
\% R=\left(1-\frac{C_{f}}{C_{p}}\right) \times 100
$$

where $C_{f}$ and $C_{0}$ are the concentration of the dye in the feed solution and the permeate $(\mathrm{mg} / \mathrm{L})$, respectively.

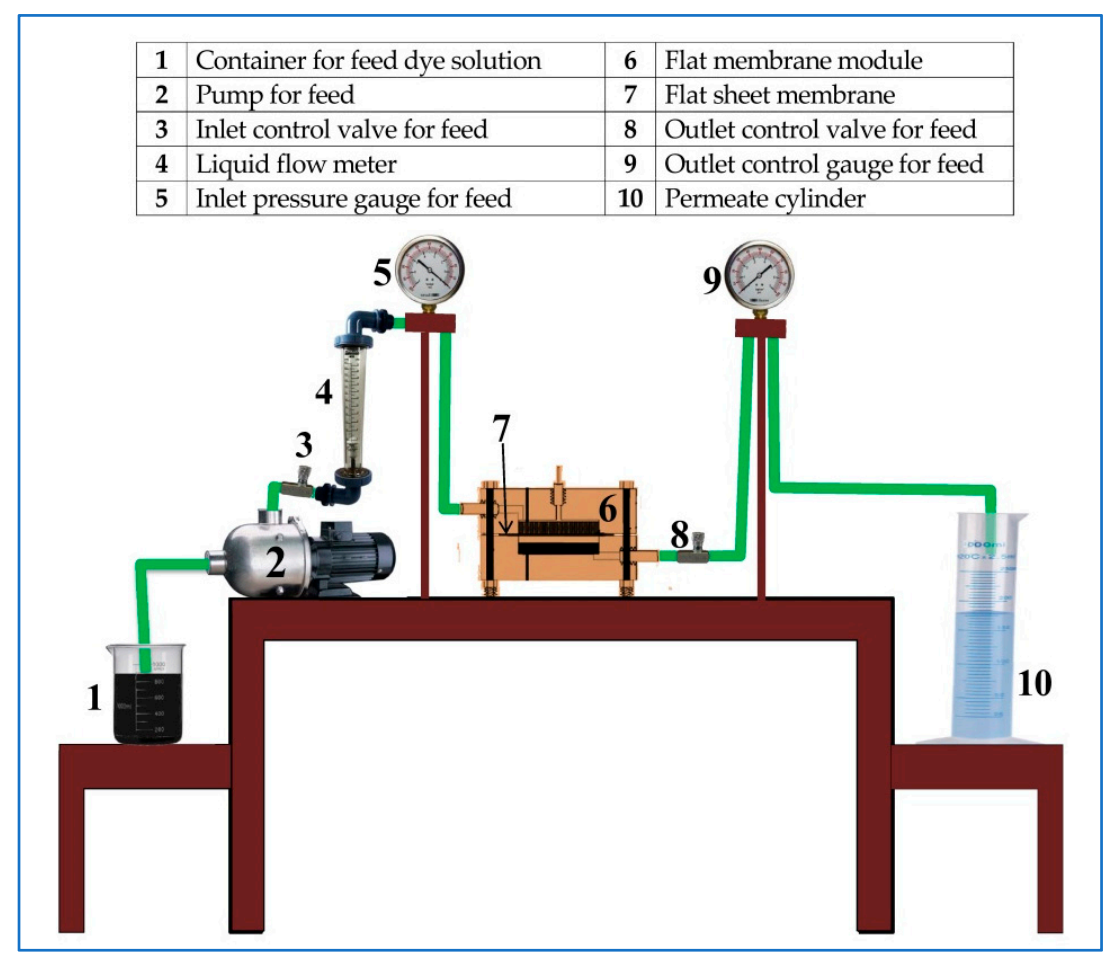

Figure 1. Schematic diagram of the cross-flow filtration rig.

After testing, the fouled membranes were washed with water three times for $30 \mathrm{~min}$, and the pure water flux of the washed membranes $\left(J w_{2}, \mathrm{~L} / \mathrm{m}^{2} \mathrm{~h}\right)$ was recorded. The flux recovery ratio $(\% F R R)$ was calculated by comparing the flux after each cleaning cycle to the pure water flux. The following equation was used to compare the fouling resistance of the fabricated membranes [43]:

$$
\% F R R=\frac{J_{2}}{J_{1}} \times 100
$$

where $J_{1}$ and $J_{2}$ are the flux $\left(\mathrm{L} / \mathrm{m}^{2} \mathrm{~h}\right)$ before and after the filtration test, respectively.

\section{Results and Discussion}

\subsection{Characterization of the Composite Membranes}

\subsubsection{FTIR-ATR Spectrum Results}

FTIR-ATR was performed to check the surface compositions of the GO and to compare the surface composition of the PES and GO-modified PES membranes. The FTIR results of the control and modified PES membranes are shown in Figure 2. The spectral peaks located at 1735, 1626, 1248, and $1050 \mathrm{~cm}^{-1}$ are attributed to the stretching vibration of the carbonyl group $-\mathrm{C}=\mathrm{O}$, the stretching vibration of the unoxidized graphitic domain $\mathrm{C}=\mathrm{C}$, and the stretching of the epoxy groups $\mathrm{C}-\mathrm{O}-\mathrm{C}$ and $\mathrm{C}-\mathrm{OH}$, respectively. The absorption peaks at the wavelengths of 3414,1556 , and $1120 \mathrm{~cm}^{-1}$ in the GO 
nanoparticles correspond to the functional groups of hydroxyl $(-\mathrm{OH})$ and carboxyl $(-\mathrm{C}=\mathrm{O}$ and $\mathrm{C}-\mathrm{O})$, respectively. FTIR affirmed the existence of different oxygen-containing functional groups, such as hydroxyl, carboxyl, carbonyl, and epoxy. These functional groups can change the membrane structure by improving its hydrophilicity [30]. The spectra also show two bands at 1078 and $1234 \mathrm{~cm}^{-1}$ that were caused by the stretching vibration of the alkoxyl $\mathrm{C}=\mathrm{O}$. The control PES membranes presented characteristic bands at 1250,1486, and $1578 \mathrm{~cm}^{-1}$ that belong to the stretching vibrations of C-O-C, aromatic bands, and the benzene ring, respectively. The peak between the range of $1290-1325 \mathrm{~cm}^{-1}$ was due to $\mathrm{O}=\mathrm{S}=\mathrm{O}[44]$.
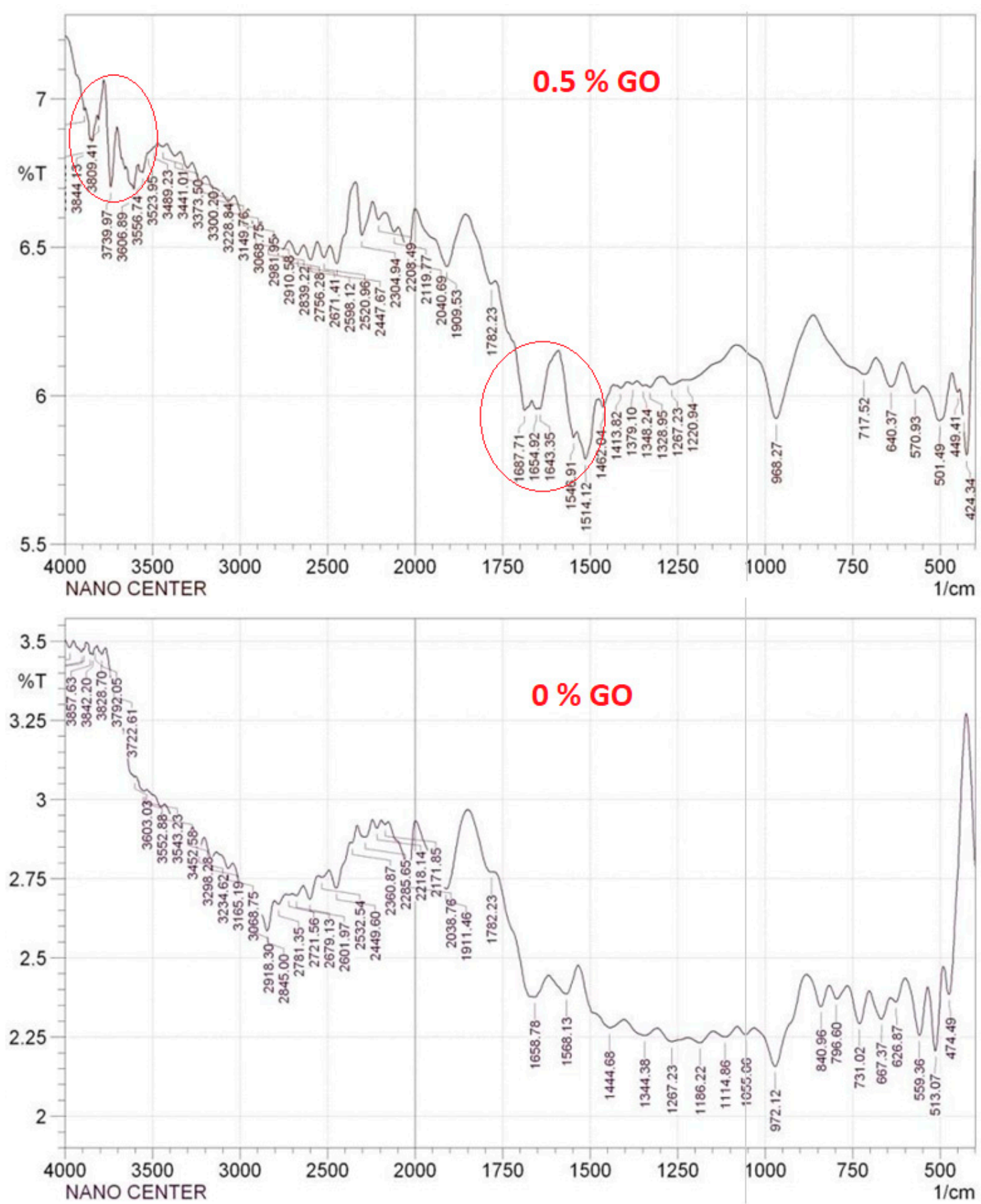

Figure 2. Fourier transform infrared-attenuated total reflection (FTIR-ATR) spectrum of the prepared membranes. 
After the GO-NPs were introduced into the PES membrane (0.5\% GO), the bands at 1627 and $1690 \mathrm{~cm}^{-1}$ were assigned to the vibration of the adsorbed water molecules and the contribution of the aromatic $\mathrm{C}=\mathrm{C}$ vibration. As shown in Figure 2, the FTIR spectra were used to confirm the generation of functional groups. Due to the asymmetric and symmetrical extension of the $\mathrm{SO}_{2}$ group, there was bonding at 1320 and $1149 \mathrm{~cm}^{-1}$. The peaks at 3097 and $3071 \mathrm{~cm}^{-1}$ corresponded to the -OH group of the carboxylic acid functional groups that are present in the GO-NPs and aromatic C-H bond stretching, respectively. The peak at $1103.94 \mathrm{~cm}^{-1}$ was attributed to the $\mathrm{C}-\mathrm{O}$ stretching bond, and the $\mathrm{C}-\mathrm{O}-\mathrm{C}$ bond was represented by the peak at $1239.13 \mathrm{~cm}^{-1}$. The peak at $2955 \mathrm{~cm}^{-1}$ corresponds to the asymmetric stretching of $\mathrm{CH}_{2}$ in the PVP.

\subsubsection{Morphology Examination by Scanning Electron Microscopy (SEM)}

Figure 3 shows cross-sectional images of the control and synthetic PES membrane with different GO contents. All the synthetic PES membranes exhibited typical symmetrical, porous structure characteristics, with the structure composed of two layers. A large layer appeared near the top edge of the membrane, with a long and thin finger-like structure. Additionally, a small layer appeared near the edge of the bottom surface, consisting of a sponge-like structure and many elliptical voids. The embedding of the GO into the casting solution at different concentrations altered the thin finger-like structure gradually into a wide finger-like structure extending to the edge of the bottom surface. The colored arrows in Figure 3 illustrate the stages of impact of the embedding of different GO amounts in the polymeric solution on the cross-sectional structure of the composite membranes. This phenomenon is attributed to the fact that GO, as a hydrophilic medium, accelerates the exchange rate between the solvent (DMSO) and nonsolvent (water as the coagulation media) during the phase inversion process, resulting in the formation of larger pores [45]. Due to the presence of hydrophilic functional groups, the migration of GO to the membrane surface will enhance the hydrophilicity of the membrane [30], which was confirmed by the FTIR-ATR results.

Figure S1 (Supplementary Information) displays the top surface images of the control and GO/PES composite membranes. As shown in Figure S1, the surface of the membrane was relatively smooth, and no pores were observed for all the prepared membranes. This phenomenon fits with our objective that the addition of the GO to the PES casting solution would accelerate the exchange rate between the solvent and nonsolvent (DMSO-water) during nascent membrane formation at a high polymer concentration in the casting solution. Therefore, a smooth-skinned, selective layer formed [43].

The elemental composition for the control and modified nanocomposite PES membranes was verified by the EDX analysis. Figure S2 illustrates the distribution of the GO taken from the top surface of the PES membrane. It can be seen that by adding different concentrations of GO-NP to the casting solution, the dispersion of the GO-NP (carbon element) in the membrane matrix improved. Most importantly, as the loading of the GO-NPs into the PES-PVP polymer casting solution increased, the $\mathrm{C}$ in the membrane matrix had a larger agglomeration. This was due to the excellent dispersibility and homogeneity of the GO in the casting solution as a result of using an ultrasonic device.

\subsubsection{Atomic Force Microscopy (AFM) and Mean Pore Radius}

Figure S3 shows the 3D atomic force microscope (AFM) measurement of the control PES and GO/PES composite membranes in the $8000 \times 8000 \mathrm{~nm}$ scanning area. In these pictures, the darker areas represent valleys or membrane pores, while the brightest areas represent the highest points on the membrane surface (e.g., nodules). The nodules of the control PES were large and connected with one another on the 3D surface. In addition, adding $0.1 \%$ by weight of GO to the PES casting solution resulted in an increase in the number of nodules. As shown in Figure S3C-E, as the GO in the casting solution further increased to $0.5 \%$ by weight, the number of nodules increased with a decrement in their size at the membrane surface. When the content of the GO was increased from $1.5 \%$ to $2 \%$ by weight, the nodules were uniformly shaped, and they were also uniformly distributed on the membrane surface, as shown in Figure S3F,G. Nodule size and density are good indicators of pore size 
and pore distribution [19]. Table 2 shows the effect of GO content on mean roughness and the mean pore radius of the control PES and GO/PES membranes.

It can be noticed that there is no clear trend of the effect of GO on membrane roughness. In general, it can be concluded that the mean roughness is decreased with the addition of GO in the casting solution. The mean pore radius of the membrane was highly enhanced from $8.25 \mathrm{~nm}$ for the control PES to $14.59 \mathrm{~nm}$ when the concentration of GO was $0.5 \mathrm{wt} \%$. With further increases in the amount of GO $(1.5 \mathrm{wt} \%)$, the mean pore radius of the composite membranes further increased to $15.59 \mathrm{~nm}$, while a slight decrease was observed with further increases in the amount of GO to $2 \mathrm{wt} \%$. This occurred due to the high hydrophilic character of GO for water, which in turn accelerated the exchange rate between the DMSO solvent and the nonsolvent water (e.g., instantaneous liquid/liquid demixing process) [46].

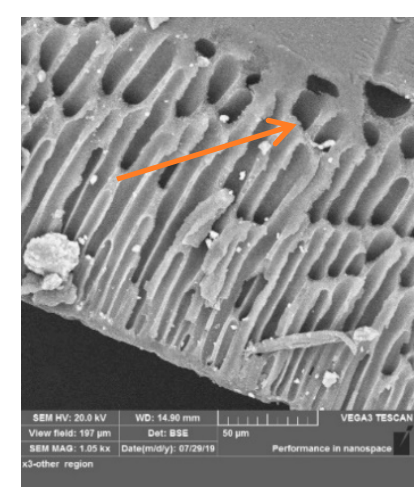

$\% 0 \mathrm{GO}$

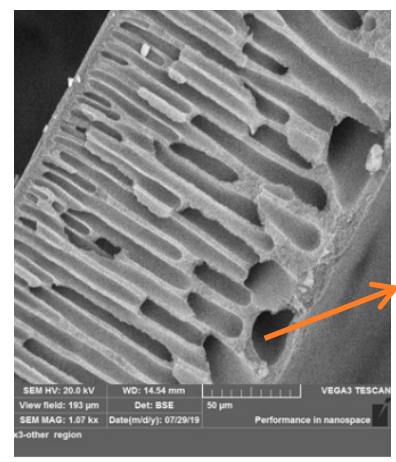

$\% 0.3 \mathrm{GO}$

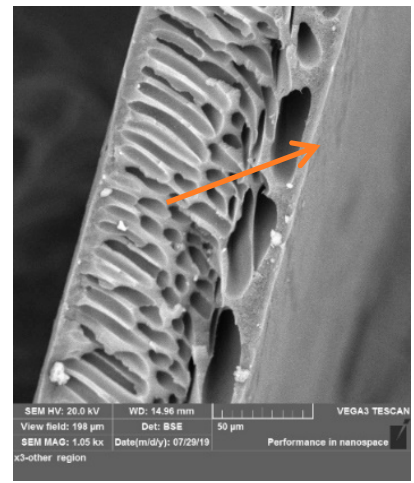

$\% 0.1 \mathrm{GO}$

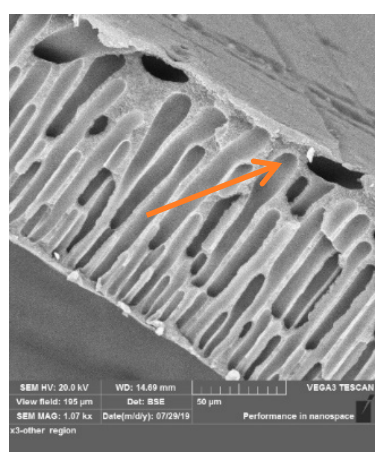

$\% 0.5 \mathrm{GO}$

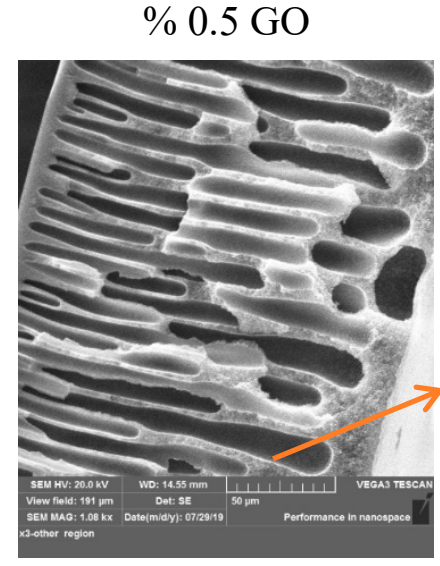

$\% 2 \mathrm{GO}$

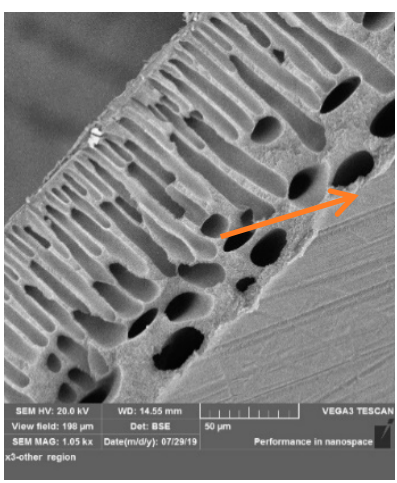

$\% 0.2 \mathrm{GO}$

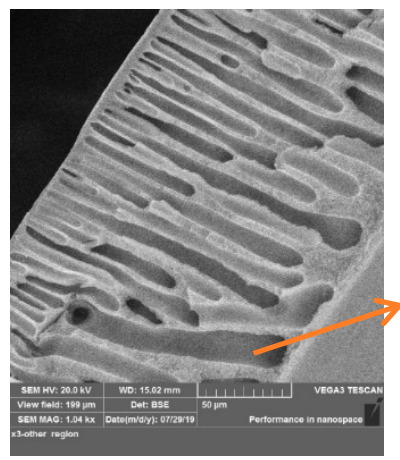

$\% 1.5 \mathrm{GO}$ 
Table 2. Mean surface pore size and roughness for the top surface of the blend membranes.

\begin{tabular}{ccc}
\hline Percent of GO in PES Membrane & Top Surface Mean Pore Radius (nm) & Mean Roughness (nm) \\
\hline 0 & 8.25 & 45.5 \\
0.1 & 5.29 & 36 \\
0.2 & 11.55 & 111 \\
0.3 & 14.06 & 77.1 \\
0.5 & 14.59 & 22 \\
1.5 & 15.59 & 41 \\
2 & 15.22 & 28.9 \\
\hline
\end{tabular}

\subsubsection{Thickness and Porosity of Pristine PES and PES-PVP-GO Membranes}

The thickness of the membrane is a key parameter that affects the membrane's performance in all membrane separation processes because the membrane thickness acts as a resistance against the mass transfer of compounds within the membrane wall. To enhance the permeation flux of the membrane in applications of ultrafiltration, the membrane must be optimally thin while taking into account the membrane's mechanical properties. In the current study, the thickness of the membranes was measured using the SEM technique, as depicted in Figure 4. The thickness of the membrane decreased from 167 to $100.88 \mu \mathrm{m}$ when $0.1 \mathrm{wt} \%$ of the GO particles was added to the casting solution. Then, the thickness increased with the addition of $0.2,0.3,0.5$, and $1.5 \mathrm{wt} \%$ of $\mathrm{GO}$ amounts to $135.89,145.16$, 150.13 , and $166.21 \mu \mathrm{m}$, respectively. As the content of the GO particles increased to $2 \%$ by weight led to a membrane structure similar to that of the net PES membrane, as shown in Figure 3, the membrane thickness did not decrease significantly. These results were due to the increase in the viscosity of the dope solution with the increasing of the concentration of GO-NPs in the casting solution. The thickness of the membrane was greatly enhanced by embedding the GO particles in the casting solution of the PES-PVP. This occurred due to the affinity of GO for water, which in turn accelerated the exchange rate between the DMSO solvent and the nonsolvent water [46].

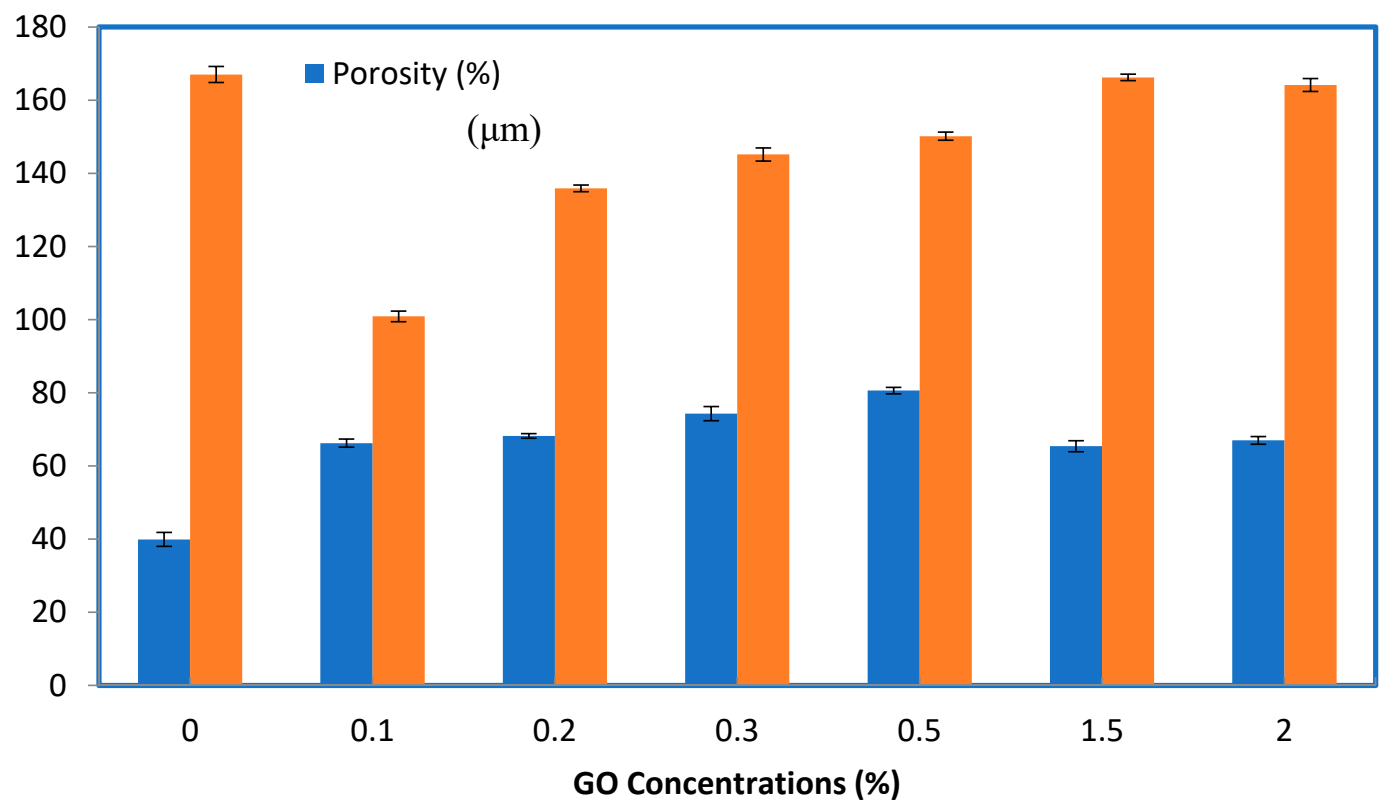

Figure 4. Effect of GO concentrations on the thickness and porosity of PES-based membranes. The bar height is the average of five measurements of porosity and thickness and the error bars represent \pm one standard deviation.

Membrane porosity is also a critical parameter that affects membrane performance. The porosity of the membranes for the control PES and GO/PES membranes at different concentrations of GO is 
displayed in Figure 4. The porosity of the membrane was highly enhanced from 39.92\% for the control PES to $80.6 \%$ when the concentration of GO was $0.5 \mathrm{wt} \%$. With further increases in the amount of GO (1.5 and $2 \mathrm{wt} \%$ ), the porosity of the composite membranes declined significantly to $65.4 \%$ and $67 \%$, respectively. These results are comparable to previous studies, where an increase in the content of hydrophilic additives led to larger void sizes and higher porosity [47]. The SEM results confirmed the measurements of the membrane thickness and porosity. Figure 4 also shows the effect of GO-NPs concentrations of the thickness of PES membranes. At lower concentrations of GO-NPs in the casting solution, the demixing process becomes faster, which in turn leads to a decrease in membrane thickness, whereas on the other hand, at higher concentrations of GO-NPs in the casting solution, the demixing process becomes slower as the concentration or content of the solid material is increased within the membrane, which leads to an increase in membrane thickness.

\subsubsection{Hydrophilicity of the PES and GO/PES Composite Membranes}

The water contact angle of the membrane is a good indicator of the hydrophilicity of the membrane. A lower contact angle indicates that the membrane surface is more hydrophilic. The contact angle results of the control PES and modified GO/PES membranes are shown in Figure 5. As observed in Figure 5, when the GO nanoparticles were added to the polymer matrix, the water contact angle decreased significantly. The control PES showed the highest water contact angle $\left(60.82^{\circ}\right)$. Adding $0.5 \%$ by weight to the casting solution reduced the water contact angle to $39.21^{\circ}$, signifying that the membrane surface is hydrophilic. After adding higher concentrations of GO (1.5 and $2 \mathrm{wt} \%)$, the contact angle increased slightly, with no significant effect in reducing the hydrophilicity of the membrane. This may be due to the aggregation of GO and the reduction in the effective surface of the particles at high mixing ratios, which in turn led to a decrease in the number of GO functional groups on the membrane surface. During the phase inversion process, the blended nanoparticles in the casting solution could migrate to the top surface of the composite membrane to reduce the interfacial energy $[45,48]$, which can be seen in GO composite membranes. The photos of the top surface of the control and the prepared membrane with a concentration of $0.5 \mathrm{wt} \%$ GO were displaced in Figure 5 . The results showed that the top surface of the composite membrane was darker than the control PES membrane which was white and clear. During the phase inversion process, as the top layer was more exposed to water, the GO particles moved to the top surface of the membrane. This migration supported more GO functional groups on the membrane surface and improved its surface hydrophilicity. Similar results have been reported in the literature for GO embedding in polysulfone membranes (PSF) [49] or carbon nanotubes (CNT) in the matrix of polyethersulfone membranes [44,50].

\subsubsection{Mechanical Properties (Tensile Strength)}

Figure 6 shows the results of the tensile strength test for the control and modified PES membranes. The membranes showed a gradual improvement in tensile strength from $0.83 \mathrm{MPa}$ for the control PES to $2.55 \mathrm{MPa}$ with $\mathrm{GO}$ at $0.5 \mathrm{wt} \%$. At lower concentrations of $\mathrm{GO}$, the tensile strength of the mixed matrix membranes increased and achieved an optimum value at 2.55 . The reason might be that a uniform distribution of the GO-NPs was achieved at a rate of $0.5 \%$. This was confirmed by the results of EDX (Figure S2 in the Supplementary Information). Therefore, a concentration of $0.5 \%$ is considered as the best addition of GO-NPs to the casting solution. Another reason for obtaining an ultimate strength at $0.5 \%$ of GO is that no agglomeration was achieved during the preparation of the casting solution as a lower concentration was used. However, at higher concentrations of GO-NPs, the tensile strength reduced to 1.67 and 1.68 at 1.5 and $2 \%$ of GO-NPs, respectively. This is due to a decrease in the movement of the polymer molecules, which increases the resistance of the material to plastic deformation [51]. 


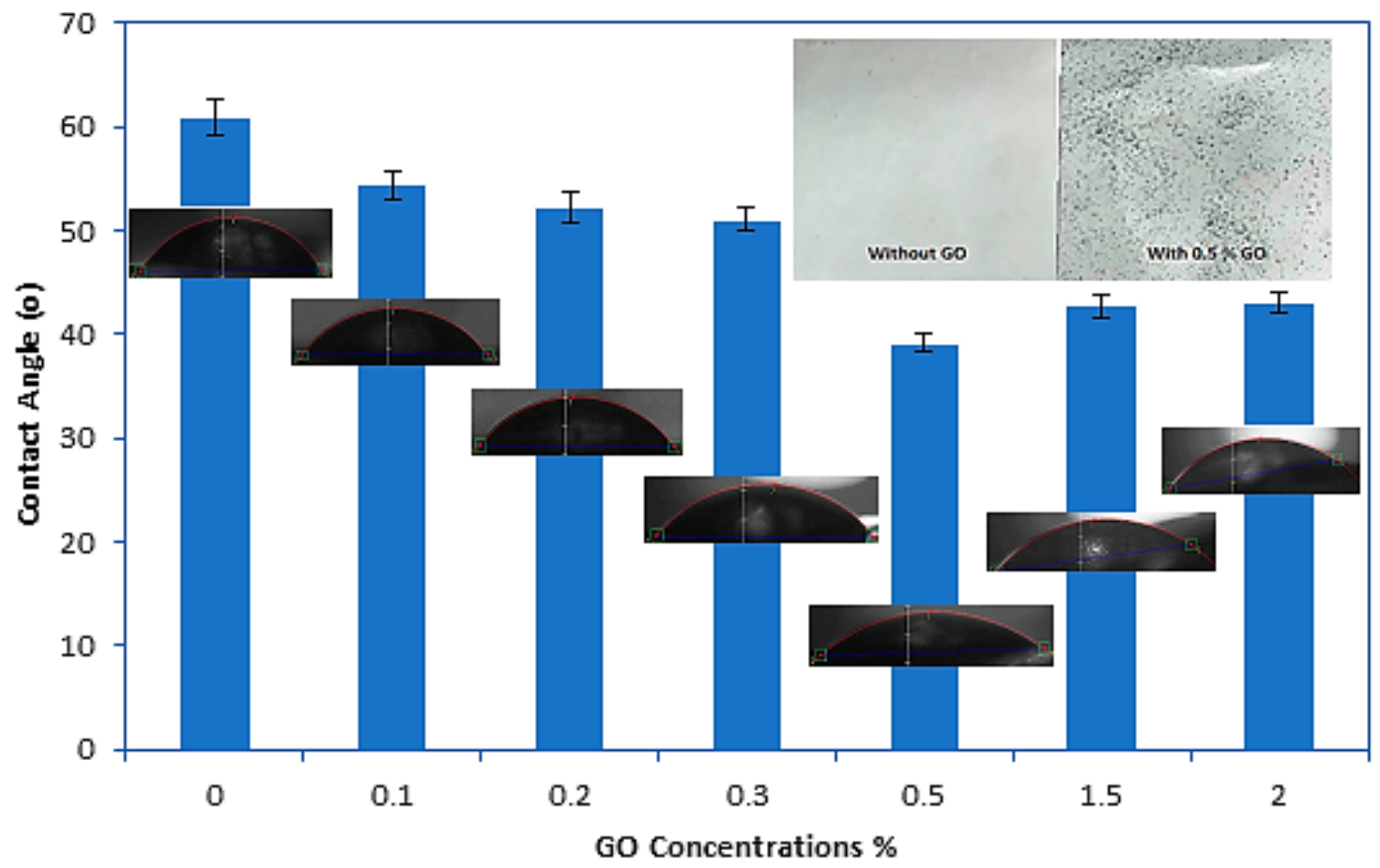

Figure 5. Contact angle measurements for control and GO-modified PES membranes with their top surface photos. The bar height is the average of five contact angle measurements and the error bars represent \pm one standard deviation.

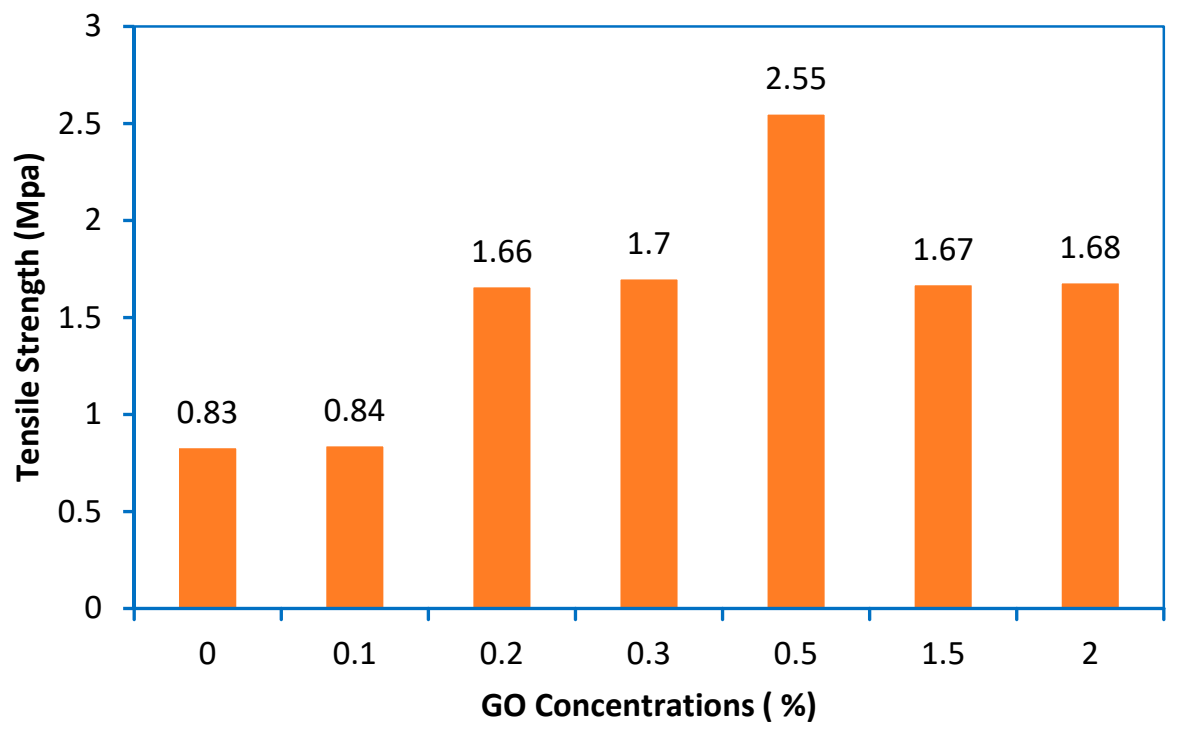

Figure 6. Effect of GO concentrations in casting solution on the tensile strength of the composite membranes.

\subsection{Performance of Various PES Membranes}

\subsubsection{Permeation Flux and Dyes Removal}

It has been documented that increasing the surface hydrophilicity will affect the permeation flux of water [30]. Figure 7 shows the results of the permeation flux of the synthesized GO/PES membrane using distilled water (DW) and the simulated wastewater of different concentrations of Acid Black dye (i.e., 10, 50, 80, and $100 \mathrm{ppm}$ ) at a pressure of 3 bar and $\mathrm{pH}=5$, with the temperature of the feed solution $25 \pm 1^{\circ} \mathrm{C}$. As shown in Figure 7, the trend of increasing water permeation flux is very consistent with decreasing contact angles (Figure 5). The permeate flux of the membrane increased as the amount of GO particles increased. When the GO content was $0.5 \mathrm{wt} \%$, the maximum water flux 
was 116.5 LMH because this membrane had the highest porosity, average pore size, and lower contact angle. However, the GO content of 1.5 and $2 \mathrm{wt} \%$ led to a decrease in the water flux to 82.3 and $83 \mathrm{LMH}$, respectively. The decrease in the permeate flux can be attributed to pore blockage caused by the high GO content [52], which indicates a decrease in porosity (Figure 4). The reason for using different concentrations of GO is to study the agglomeration phenomena of nanoparticles within the membranes. In fact, the agglomeration of nanoparticles is a serious problem and would lead to undesirable changes in the properties of the membrane, including lower water flux and weakening membrane mechanical strength. Therefore, to avoid this problem, a lower concentration of nanoparticles is recommended and proposed by many researchers.

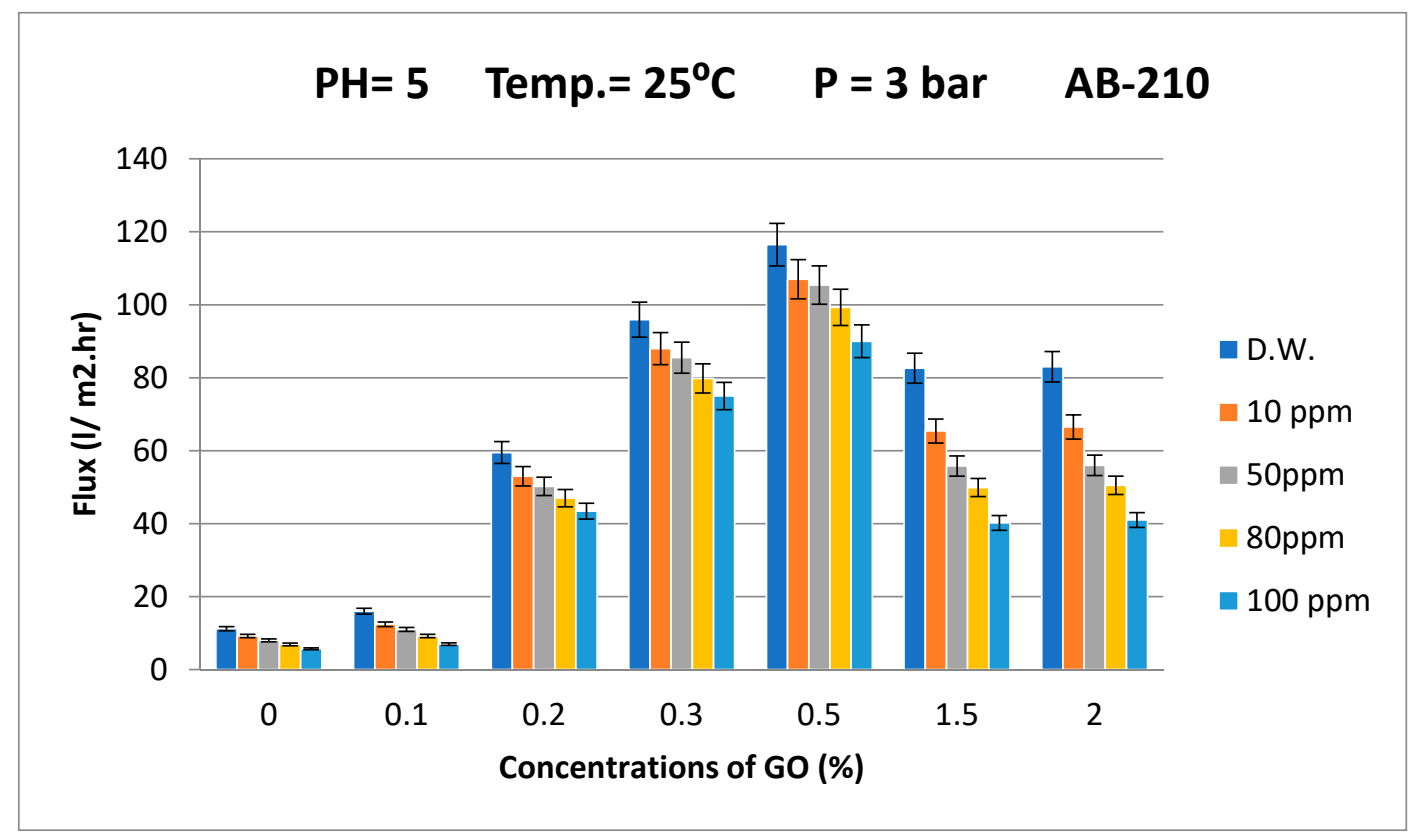

Figure 7. Effect of the Acid Black dye concentration in feed solution on the permeation flux of the membrane prepared at different GO concentrations. The bar height is the average of five measurements of permeation flux and the error bars represent \pm one standard deviation.

The hydrophilic effect of GO can increase the exchange rate between the solvent and nonsolvent during membrane formation [45]. This leads to higher porosity on the membrane surface (Figure 7) and enhances the permeation flux of water (Figure 7). However, when the GO concentration was higher than $0.5 \mathrm{wt} \%$, the viscosity of the coating solution increased, which led to a decrease in the pore size and the porosity of the membrane [53] and may lead to a decrease in the water permeation flux. A similar behavior was observed by Wang et al. [31] for GO-modified PVDF membranes.

The permeation flux of Acid Black (AB-210) dye at different concentrations declined moderately, meaning that embedding GO in the membrane matrix minimized the effects of fouling. For example, at a 10-ppm concentration of Acid Black dye, the flux reduction was only $8.12 \%$ compared with the pure water flux of the membrane prepared for $0.5 \mathrm{wt} \% \mathrm{GO}$, while for the control PES membrane, the flux reduction at 10 ppm of Acid Black dye was $17.85 \%$. These discrepancies can be attributed to the hydrophilicity and antifouling characteristics of the developed membranes. Additionally, it is well-known that increasing the concentration of the dye in the wastewater reduces the permeation flux across the membrane. Therefore, there was a negative effect on the permeation flux when increasing the dye concentration in wastewater of all the control and GO/PES composite membranes.

From Figure 7 , it can be concluded that the results of the permeation flux of the membranes prepared from 1.5 and $2 \mathrm{wt} \%$ GO were approximately the same or lower than for the membrane prepared from $0.5 \mathrm{wt} \% \mathrm{GO}$. The optimum concentration of GO particles should not be more than 
$0.5 \mathrm{wt} \%$, which was confirmed by the results of the dye rejection, which will be discussed in the next section.

Figure 8 shows the results of the membrane performance of the control PES and GO/PES composite membranes for distilled water and simulated wastewater of different concentrations of Rose Bengal (RB) dye (e.g., 10, 50, 80, and $100 \mathrm{ppm}$ ) at a pressure of $3 \mathrm{bar}, \mathrm{pH}=5$, and feed solution temperature of $25 \pm 1{ }^{\circ} \mathrm{C}$. The permeation flux of the control PES and modified PES/GO membranes at various concentrations of Rose Bengal dye were substantially lower than the permeation flux of the Acid Black dye solution. For example, the reduction in the permeation flux at a 10-ppm concentration of Rose Bengal dye was $14.3 \%$ compared with the pure water flux of the membrane prepared from $0.5 \mathrm{wt} \% \mathrm{GO}$. However, for the pristine PES membrane, the flux reduction at 10 ppm Rose Bengal dye was $23.27 \%$, which represents a higher reduction in the permeation flux than for the pristine PES membrane used for the Acid Black dye.

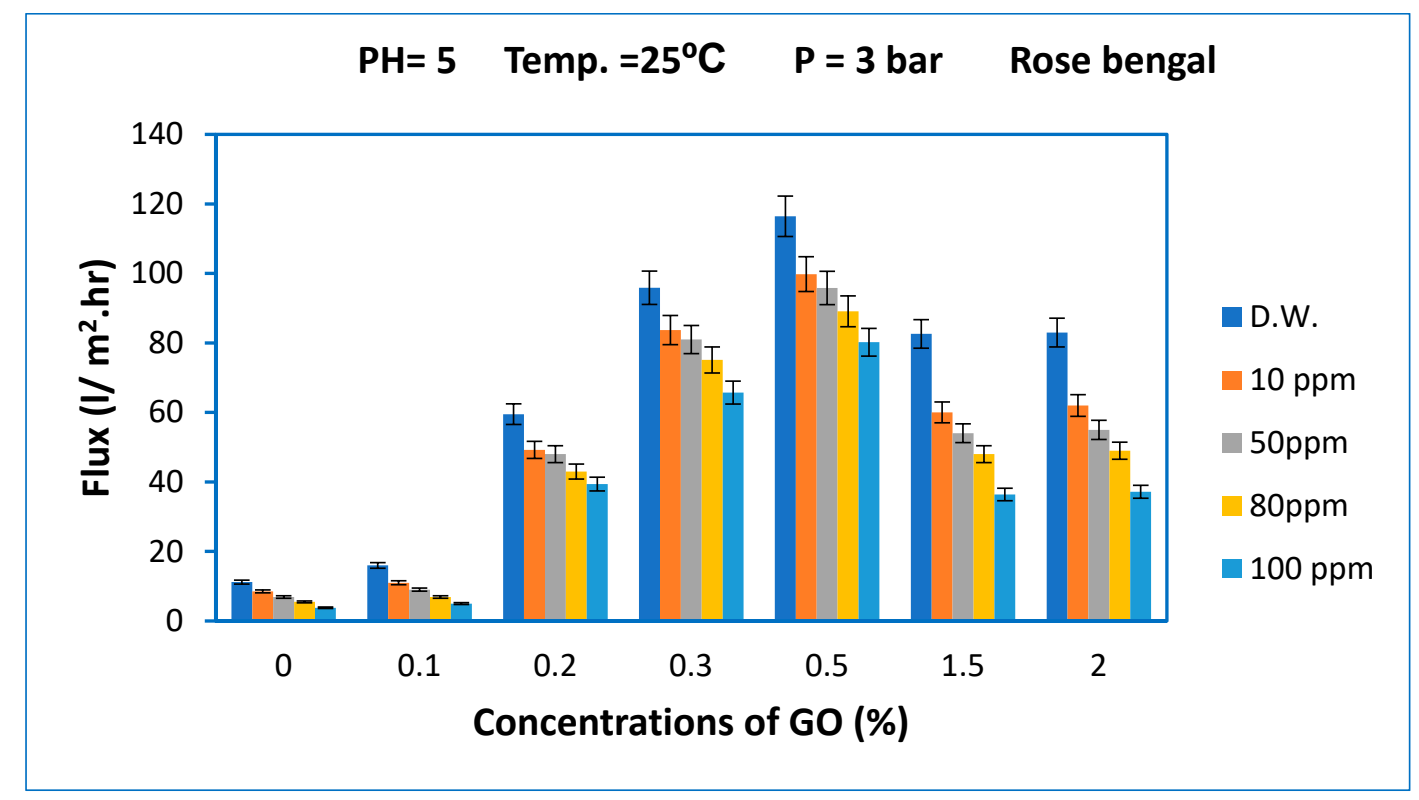

Figure 8. Effect of the Rose Bengal dye concentration in feed solution on the permeation flux of the membrane prepared at different GO concentrations. The bar height is the average of five measurements of permeation flux and the error bars represent \pm one standard deviation.

Figure 9 illustrates the dye removal efficiency (\%R) of the control PES and PES-PVP-GO membranes for a 50-ppm dye concentration in simulated wastewater, $\mathrm{pH}=5$, and feed solution temperature of $25 \pm 1{ }^{\circ} \mathrm{C}$. The removal efficiency (\%R) of the Acid Black dye was $88 \%$ for the control PES membrane, which highly improved to $99 \%$ for the membrane prepared from $0.1 \mathrm{wt} \% \mathrm{GO}$. The removal efficiency was between $99.4 \%$ and $99.7 \%$ for any further increase in the contents of GO. Whereas the removal efficiency of the control PES membrane for the Rose Bengal dye was $86 \%$, it improved to $96.2 \%$ with an addition of $0.1 \mathrm{wt} \% \mathrm{GO}$. Using $0.2 \mathrm{wt} \% \mathrm{GO}$ in the casting solution increased the removal efficiency to $97 \%$, while further increases in the GO amounts (e.g., $0.3,0.5,1.5$, and $2 \%$ ) resulted in an improvement in the removal efficiency of between $98.9 \%$ and $99 \%$, as depicted in Figure 9 . For both types of dyes, the removal efficiency (\%R) of the PES-PVP-GO membranes was substantially better than that of the membrane fabricated from the control PES membrane. 


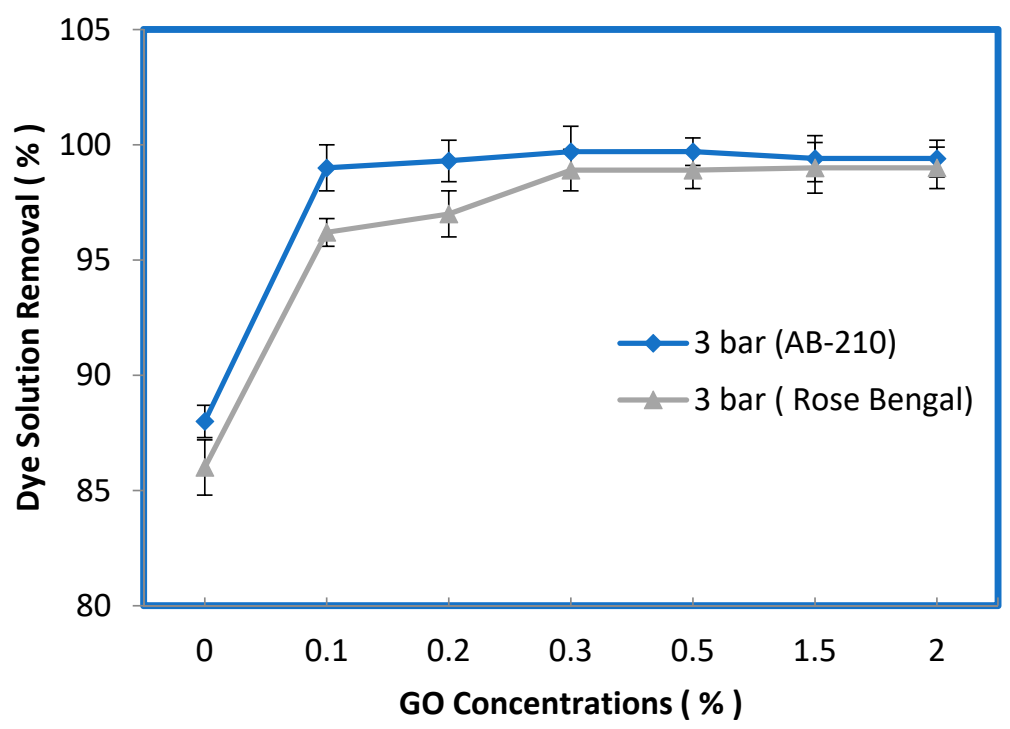

Figure 9. Effect of the dye concentration in feed solution on the dye removal efficiency ( $\mathrm{R} \%)$ of the membrane prepared at different GO concentrations.

The negative hydrophilic functional groups on the GO surface, such as hydroxyl (-OH) and carboxyl $(-\mathrm{COOH})$, can create a high zeta potential by generating negative charges on the membrane surface. The negative charge of the Acid Black dye and the negative charge on the membrane surface will increase the repulsive force, which leads to an increase in the rejection rate of the dye [54]. The control PES membrane does not function in this manner. Fundamentally speaking, the charge that repels the dye depends on the membrane charge, ionic strength, and ionic capacity [45], which is due to the greater repulsion between the dye and the functional groups of the embedded nanomaterial. In addition, some researchers have proposed that due to a strong bond with water, a modified hydrophilic membrane can effectively prevent molecules from passing through [55].

\subsubsection{Integrity and Stability of the PES Membranes during Long-Term Performance}

Under extreme conditions (such as pressure and temperature), periodic exposure of the membrane to the cleaning agent will negatively affect the physical properties of the membrane, which in turn may affect the performance of the membrane. As such, the quality and quantity of products may be affected. In addition, in a cross-flow system, contamination may occur in the membrane module, and the contamination cannot be effectively removed through an organized process. Therefore, it is often necessary to study the life of the reusable membrane to ensure that the membrane will not collapse over time during the filtration process, where it can affect the products and even the process itself [14]. Therefore, this work also investigated the long-term consequences of processing two dyes using membranes fabricated from the control PES and PES-PVP-GO with $0.5 \mathrm{wt} \% \mathrm{GO}$, finding that the GO/PES membrane provided optimal performance. Figure 10 depicts the long-term UF operation carried out for the $0.5 \mathrm{wt} \%$ GO (GO/PES) membrane at a pressure of 3 bar and feed temperature of $25{ }^{\circ} \mathrm{C}$ for $50-\mathrm{ppm}$ Acid Black and Rose Bengal dye solutions. Figure 10 demonstrates that the permeation flux of the Acid Black solution using the control PES membrane was stable between 13 and $15.1 \mathrm{~L} / \mathrm{m}^{2} \cdot \mathrm{h}$ throughout the UF operation for $14 \mathrm{~d}$ before the permeation flux began to decline. In contrast, the long-term operation of the membrane fabricated from $0.5 \mathrm{wt} \% \mathrm{GO}$ using an Acid Black dye solution improved greatly over $26 \mathrm{~d}$, and the permeation flux remained stable between 85.2 and $80 \mathrm{~L} / \mathrm{m}^{2} \mathrm{~h}$. 


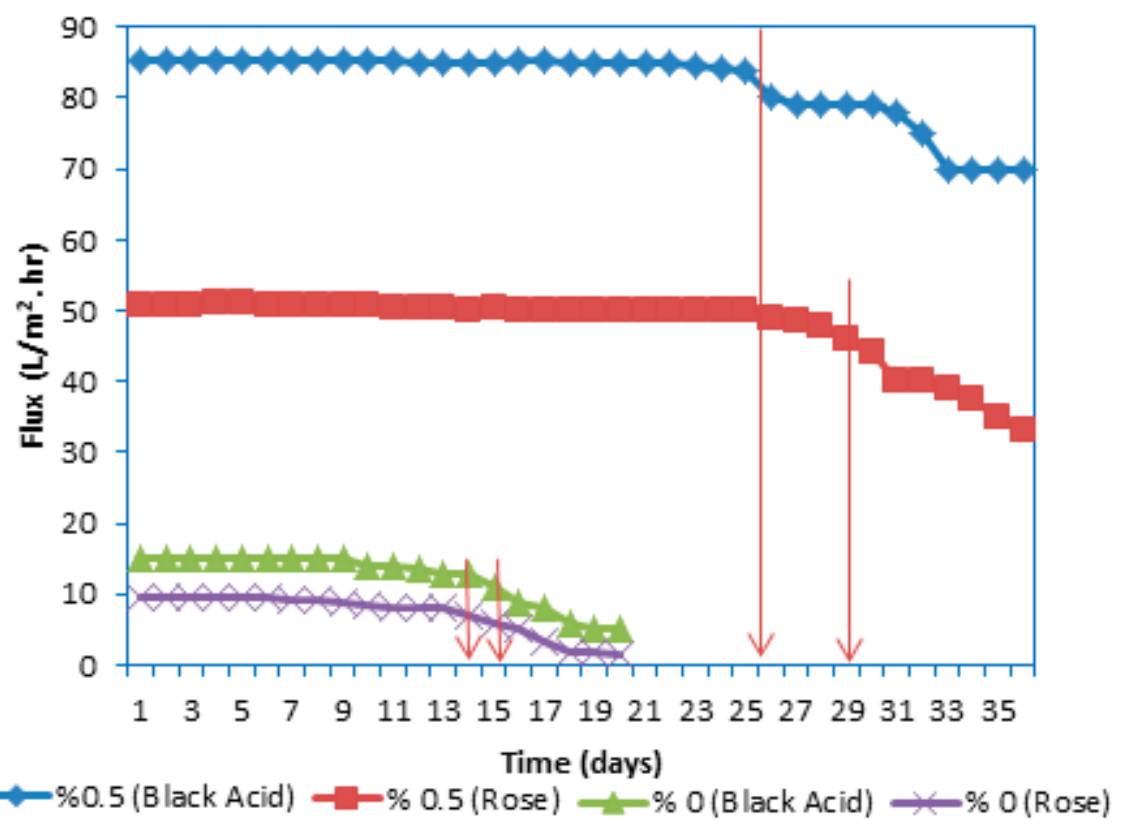

Figure 10. The effect of GO in casting solution on long-term of the prepared membrane.

For the Rose Bengal dye solution, the permeation flux of the control PES membrane was stable throughout the UF operation between 9.7 and $8 \mathrm{~L} / \mathrm{m}^{2} \mathrm{~h}$ for $14 \mathrm{~d}$. Additionally, the long-term operation of the membrane fabricated from $0.5 \mathrm{wt} \% \mathrm{GO}$ using the Rose Bengal dye solution was highly enhanced by $26 \mathrm{~d}$, and the permeation flux remained stable between 50.8 and $49 \mathrm{~L} / \mathrm{m}^{2} \mathrm{~h}$. The hydrophilic nature of the GO particle was the main reason for the permeate flux stability of this membrane. However, the results of the long-term performance test indicate the feasibility of using GO as an additive in the GO/PES membrane for efficient dye removal from wastewater treatment using the UF process. The main reason for long and stable performance during the long-term UF operation was the GO embedded in the membrane matrix, where the GO acted as an effective antifouling material, which in turn protected the thickness of the membrane wall. Additionally, the reason for the stable performance was attributed to the excellent mechanical properties of GO, as was discussed previously in Section 3.1.6. "Mechanical properties (tensile strength)".

\subsubsection{Flux Recovery Efficiency}

The membrane used in the ultrafiltration system should be able to restore its water permeability after contact with wastewater. Therefore, it is necessary to evaluate and compare the flux before and after ultrafiltration. After completing the long-term performance experiment, the flat sheet PES-UF membrane was backwashed with pure water for $9 \mathrm{~h}$ at 3 bar, after which the pure water flux was measured again (see Figure 11). Figure 11 shows that the water flux after backwashing was lower than that in Figure 7, which was caused by the dye and contaminants remaining on the surface of each membrane. This phenomenon will cause a sudden drop in flux during long-term operation. In contrast, for the $0.5 \mathrm{wt} \% \mathrm{GO}$ concentration, the adsorption effect between the dye pollutant and the membrane was very weak because of the beneficial hydrophilic property of the membrane; therefore, the dye can be easily washed away from the membrane surface containing the GO particles after the backwash. Finally, the membrane surfaces returned to being white in color, and the pure water flux recovered. 


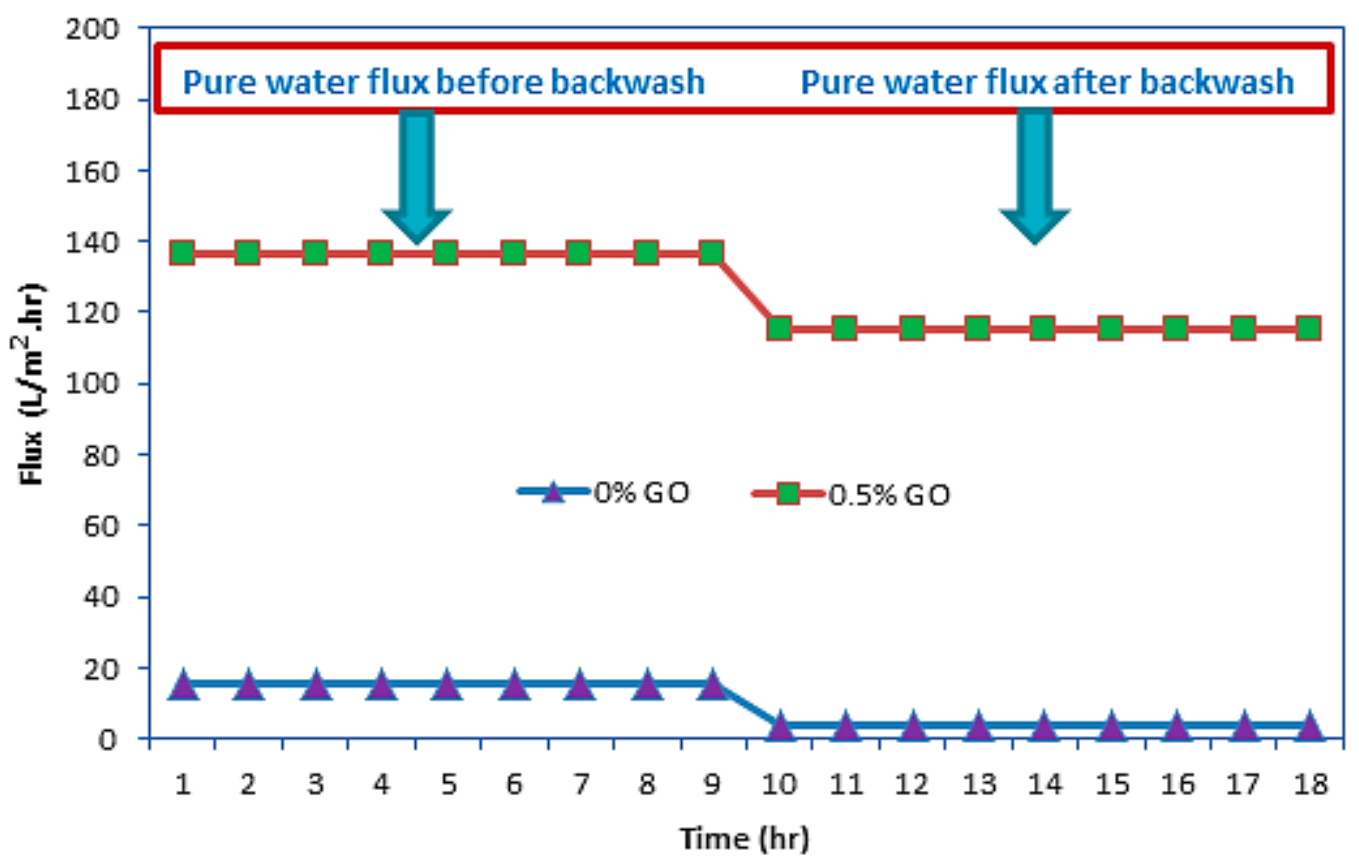

Figure 11. Pure water flux before and after backwashing for $18 \mathrm{~h}$ at pressure of $3 \mathrm{bar}$.

\subsubsection{Effect of the Feed $\mathrm{pH}$ on the Permeation Flux and Dye Removal}

Changing the zeta potential by changing the $\mathrm{pH}$ of the solution can critically influence the performance of the membrane separation. Measurements of zeta potential are not only essential for obtaining insight into the retention mechanisms for disparate charged solutes but also for understanding membrane aging, fouling, functionalization, and cleaning. Changing the $\mathrm{pH}$ value will not only dissociate the surface functional groups but also induce the membrane to acquire a charge from the adsorbed molecules in the feed [56]. The $\mathrm{pH}$ of the feed solution could influence the degree of ionization and speciation of the dyes [57]. A wide range of $\mathrm{pH}$ values (from 3 to 11) was employed to examine the membranes' performance behavior in terms of their permeate flux against both dyes. As displayed in Figure 12, there was a clear influence of the $\mathrm{pH}$ on the permeate flux of the blended membrane prepared from $0.5 \%$ GO (i.e., the optimum concentration). However, a slight decrease in the permeation flux was observed at $\mathrm{pH}=7$, while beyond this value at a higher $\mathrm{pH}$, the decline of the permeation flux became more significant for both dyes at all concentrations (i.e., 10, 50, 80, and $100 \mathrm{ppm}$ ). Interestingly, the pure water flux did not manifest any change, indicating that PES membranes can tolerate a wide $\mathrm{pH}$ range. Additionally, a higher flux decline was observed at higher concentrations (e.g., $100 \mathrm{ppm}$ ). This was probably caused by the dissociation of the functional groups of the organic dyes, along with the dissociation of the membrane surface. Indeed, reducing the interactions between the membrane surface and these molecules would have accelerated their deposition on the surface. The removal rates were calculated for both dyes at the optimum concentration $(0.5 \% \mathrm{GO})$ at different $\mathrm{pH}$ levels. Figure 13 illustrates the impact of $0.5 \mathrm{wt} \% \mathrm{GO}$ on the removal \% of both dyes. As shown in Figure 13, different concentrations of the AB-210 and RB dyes were used. The rate of dyes removal decreases gradually by increasing the concentration of the dye as well as for the relationship between $\mathrm{pH}$ with the rate of removal where the rate of dyes removal decreases significantly by increasing the value of $\mathrm{pH}$ (basic condition). Additionally, the dye removal \% for Rose Bengal was lower than the dye removal $\%$ for Acid Black-210 because the molecular weight of Rose Bengal $(1017 \mathrm{~g} / \mathrm{mol})$ is slightly higher than that of AB-210 $(938.017 \mathrm{~g} / \mathrm{mol})[58,59]$.

Moreover, according to the zeta potential measurements displayed in Figure 14, the two dyes possess negative surface energy. Therefore, the two anionic AB-210 and Rose Bengal dyes showed less degradation due to the lower binding affinity caused by their negative charge. Furthermore, because of 
the acidic functional groups of GO, it can prompt negative charge on the membrane composite surface, causing high rejection between negative surface and negative dye.
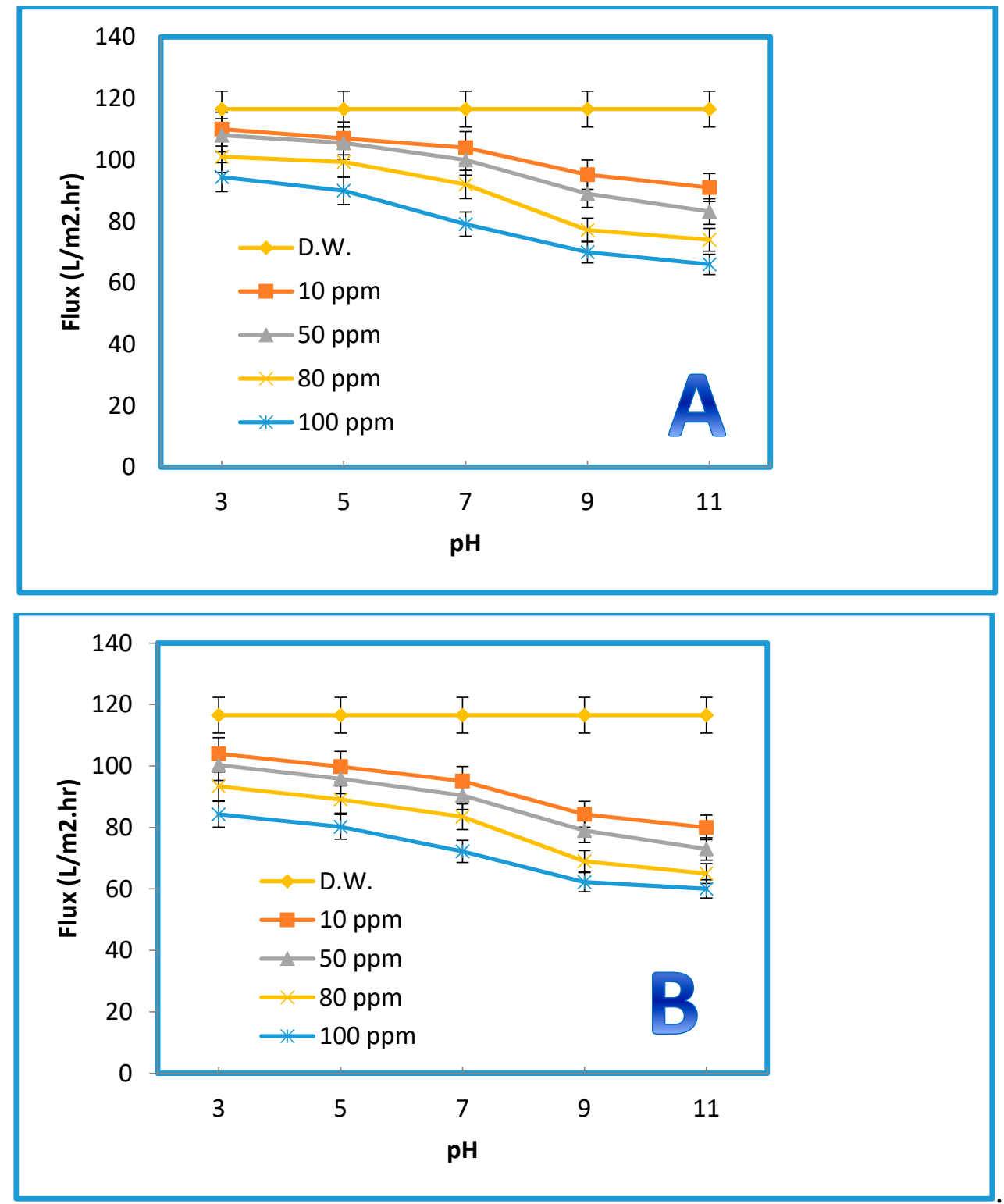

Figure 12. Effect of $\mathrm{pH}$ on the permeation flux of membrane prepared from $\% 0.5 \mathrm{GO}$, at $3 \mathrm{bar}, 25{ }^{\circ} \mathrm{C}$, for Acid Black (AB-210) (A) and Rose Bengal (RB) (B). 

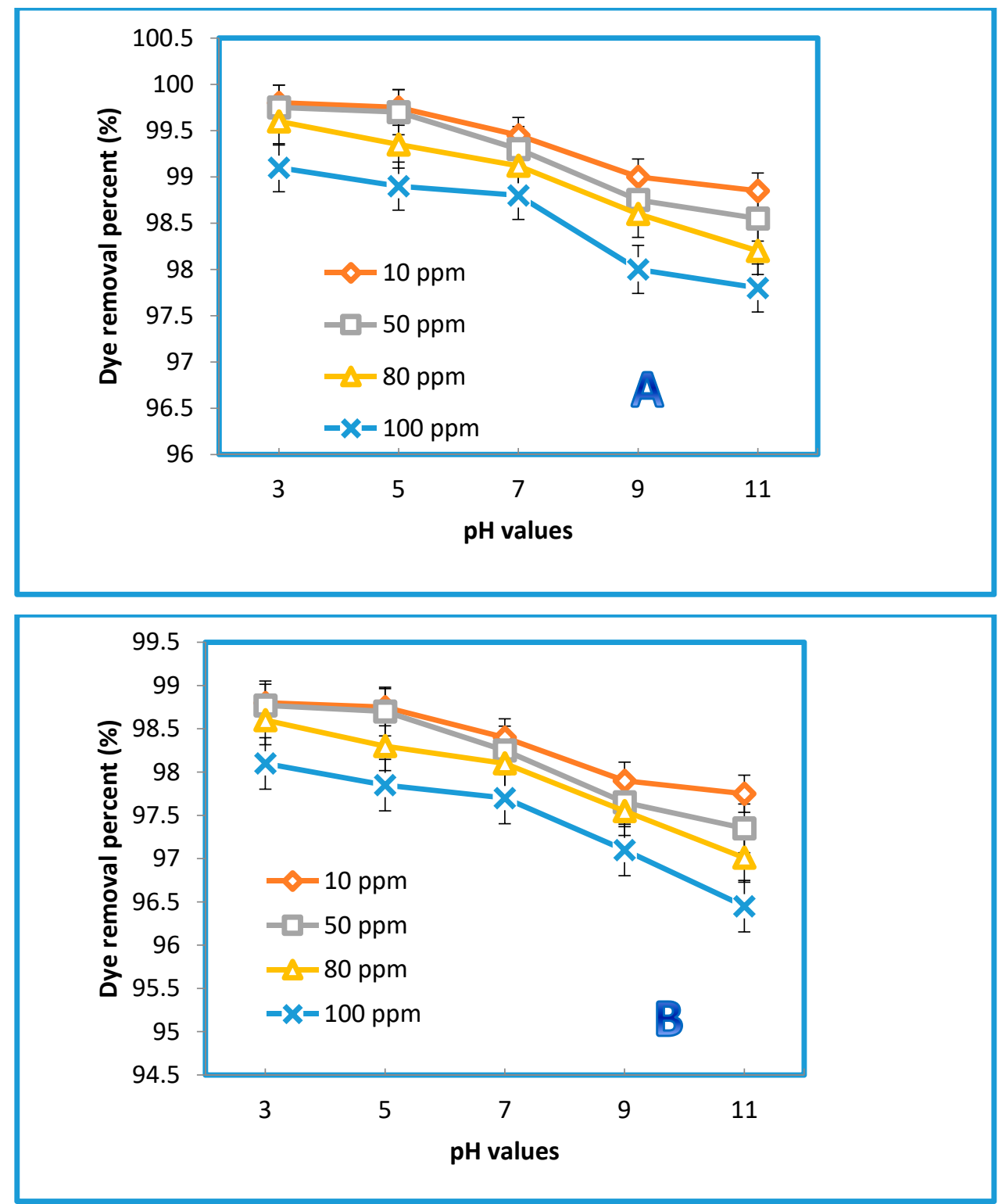

Figure 13. Effect of $\mathrm{pH}$ on the dye removal percent of membrane prepared from $\% 0.5 \mathrm{GO}$, at 3 bar, 25 ${ }^{\circ} \mathrm{C}$, for AB-210 (A) and RB (B).

To highlight the novelty of this work, a comprehensive comparison of membrane separation performance with other reported/published data is presented in Table 3. This comparison was made with the recent reported data found in the literature based on permeation water flux (PWF) and the solute rejection rate (\%R) of GO mixed matrix membranes (MMMs). Relatively few polymers combined with different concentrations of GO-NPs have been recently reported for ultrafiltration applications. From Table 3, it can be distinguished that the membranes synthesized in the present work, with the operating parameters discussed in Section 2.3. "Preparation of the membrane" from GO mixed matrix membranes (MMMs), have acceptable permeation water flux and higher rejection of contaminates. 


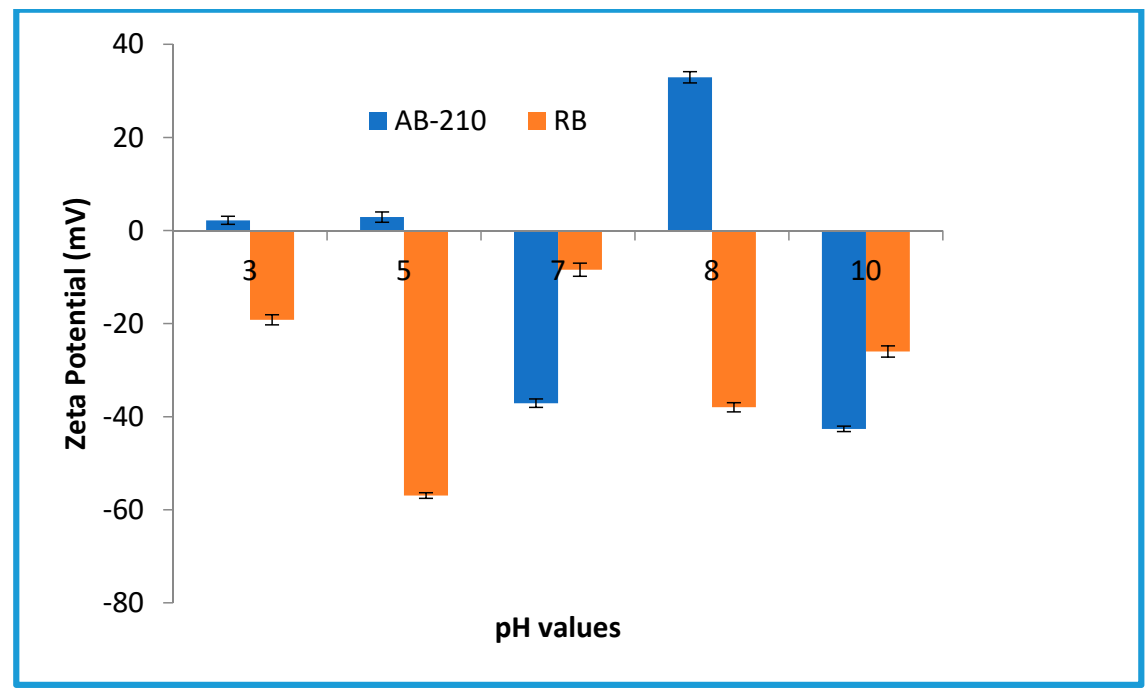

Figure 14. Dependence of zeta potential of dye solutions on $\mathrm{pH}$ value.

Table 3. Demonstrates the comparison of this work with the recent published GO mixed matrix membranes.

\begin{tabular}{|c|c|c|c|c|c|}
\hline $\begin{array}{l}\text { Polymer } \\
\text { (wt.\%) }\end{array}$ & Fillers (wt.\%) & $\begin{array}{l}\text { Pore-Formers } \\
\text { PVP (wt.\%) }\end{array}$ & $\begin{array}{l}\text { Permeate } \\
\text { (LMH bar) }\end{array}$ & Rejection (\%) & Ref. \\
\hline PES (16) & *Cu(TPA)@GO & PVP (2) & $24-75$ & $\begin{array}{l}15 \% \text { Methyl blue } \\
65 \% \text { Methyl orange } \\
90 \% \text { Congo red }\end{array}$ & [32] \\
\hline PES (18) & $\begin{array}{l}\text { sulfonated-GO } \\
\text { (1) }\end{array}$ & PVP (1) & 9.1 & $\begin{array}{c}\text { 83.9\% Acid blue } \\
\text { 83.5\% Bismark Brown }\end{array}$ & [33] \\
\hline PES (20) & GO (0.3) & T904 (5) & 245 & $\begin{array}{l}62.3 \% \text { sunset yellow (SY) } \\
\text { dye } \\
35.4 \% \text { acridine orange } \\
\text { (AO) dye }\end{array}$ & [34] \\
\hline PES (18) & GO $(0.008)$ & PVP (1) & 289.86 & $86.58 \%$ methyl red & [35] \\
\hline PES (16) & $\begin{array}{c}\text { * APTS-GO } \\
(0.1)\end{array}$ & PVP-40 (1) & 9.9 & $\begin{array}{c}97.4 \% \mathrm{SY} \\
96.5 \% \mathrm{AO} \\
51.6 \% \mathrm{MgSO}_{4}\end{array}$ & [36] \\
\hline PSf (16) & GO (0-5) & $\begin{array}{l}\text { No additive } \\
\text { used }\end{array}$ & $87.5-150$ & No rejection data & [37] \\
\hline PSf (15) & $\begin{array}{c}\text { Janus GO } \\
(0.1-1)\end{array}$ & $\begin{array}{l}\text { No additive } \\
\text { used }\end{array}$ & $11.5-115$ & $92 \%$ BSA & [38] \\
\hline PVDF (15) & GO (0-2) & PVP (1) & 188.36 & $52 \%$ BSA & [39] \\
\hline PVDF (12) & $\begin{array}{c}\mathrm{GO}(0.5,1 \text { and } \\
2 \%)\end{array}$ & PVP (5) & 552.92 & $\begin{array}{c}87.11 \% \mathrm{COD} \\
93.75 \% \mathrm{NH}_{4}-\mathrm{N}\end{array}$ & [40] \\
\hline PES (21) & $\begin{array}{l}\text { GO }(0.1-2) \\
\text { wt. } \%\end{array}$ & PVP (1) & 116.5 & $\begin{array}{l}\text { 99.7\% Acid black (AB) dye } \\
\text { 99\% Rose Bengal dye (RB) }\end{array}$ & This work \\
\hline
\end{tabular}

* APTS is defined as aminopropyltriethoxysilane; TPA is defined as Terephthalate.

\section{Conclusions}

In the present work, GO nanoparticles were successfully synthesized and then applied to modify PES and PVP UF membranes without the agglomeration of GO. Different amounts of GO particles (i.e., 0.1, $0.2,0.3,0.5,1.5$, and $2 \mathrm{wt} \%$ ) were added to the casting solution during the phase inversion process to obtain modified composite membranes, and PES/GO flat-sheet membranes were prepared and used to remove dyes from simulated leather tanning and textile industries' wastewater.

Adding GO particles to the PES casting solution changed the morphological structure of the membrane and significantly increased the mean pore radius. Due to the increase in the hydrophilicity of the particles, the pure water permeability (PWP) of the membrane increased after the addition of 
the GO particles. The CA value of the top surface decreased from $60.82^{\circ}$ of the control PES to $39.21^{\circ}$ when the content of the GO particles increased to $0.5 \mathrm{wt} \%$. This is due to the GO particles moving towards the surface during the membrane formation process, which in turn makes the surface more hydrophilic. Therefore, the mechanical strength of the composite membrane can be slightly improved, which can be attributed to the reinforcing effect of the inorganic filler. The tensile strength of the PES membrane increased by about $69 \%$ after the addition of $0.5 \mathrm{wt} \%$ of GO-NPs to the casting solution in comparison to the control PES membrane.

The pore structures and the negative charge of the nanomaterial led to an increase in the permeability to about $88 \%$ at the optimal amount of $0.5 \mathrm{wt} \%$ GO nanomaterial. Additionally, the addition of GO to the PES casting solution resulted in longer lifetimes of the membranes due to enhancement in the fouling resistance and flux recovery efficiency (FRE) after backwashing.

The dye removal was higher than $99 \%$ for all the membranes studied and both dyes (AB-210 and $\mathrm{RB})$, at dye concentrations of 10,50, 80, and $100 \mathrm{ppm}$ and an operating pressure of 3 bar. These conditions can be utilized in the decolorization and dye purification of wastewater.

Supplementary Materials: The following are available online at http://www.mdpi.com/2077-0375/10/12/366/s1.

Author Contributions: Conceptualization, Q.F.A. and F.H.A.-A.; methodology, Q.F.A. and M.A.-s.; validation, Q.F.A., F.H.A.-A. and A.F.; formal analysis, R.J.K. and Q.F.A.; investigation, R.J.K.; data curation, R.J.K., Q.F.A.; writing-original draft preparation, Q.F.A. and R.J.K.; writing-review and editing, Q.F.A. and F.H.A.-A. and M.A.-s.; visualization, Q.F.A. and A.F.; supervision, Q.F.A. and F.H.A.-A. All authors have read and agreed to the published version of the manuscript.

Funding: This research received no external funding.

Conflicts of Interest: The authors of the current work do not have any conflicts of interest.

\section{References}

1. Petersen, L.; Heynen, M.; Pellicciotti, F. Freshwater Resources: Past, Present, Future. Int. Encycl. Geogr. 2017, 1-11. [CrossRef]

2. Lin, J.; Ye, W.; Baltaru, M.C.; Tang, Y.P.; Bernstein, N.J.; Gao, P.; Balta, S.; Vlad, M.; Volodin, A.; Sotto, A.; et al. Tight ultrafiltration membranes for enhanced separation of dyes and $\mathrm{Na}_{2} \mathrm{SO}_{4}$ during textile wastewater treatment. J. Membr. Sci. 2016, 514, 217-228. [CrossRef]

3. Van Der Bruggen, B. Mechanisms of retention and flux decline for the nanofiltration of dye baths from the textile industry. Sep. Purif. Technol. 2001, 22, 519-528. [CrossRef]

4. Koyuncu, I. Reactive dye removal in dye/salt mixtures by nanofiltration fibers containing vinylsulphone dyes: Effects of feed concentration and cross flow velocity. Desalination 2002, 143, 243-253. [CrossRef]

5. Majewska-Nowak, K. Ultrafiltration of dye solutions in the presence of cationic and anionic surfactants. Environ. Prot. Eng. 2009, 35, 111-121.

6. De Gisi, S.; Lofrano, G.; Grassi, M.; Notarnicola, M. Characteristics and adsorption capacities of low-cost sorbents for wastewater treatment: A review. Sustain. Mater. Technol. 2016, 9, 10-40. [CrossRef]

7. Moussavi, G.; Mahmoudi, M. Removal of azo and anthraquinone reactive dyes from industrial wastewaters using $\mathrm{MgO}$ nanoparticles. J. Hazard. Mater. 2009, 168, 806-812. [CrossRef]

8. Yaseen, D.A.; Scholz, M. Textile dye wastewater characteristics and constituents of synthetic effluents: A critical review. Int. J. Environ. Sci. Technol. 2019, 16, 1193-1226. [CrossRef]

9. Pendergast, M.M.; Hoek, E.M.V. A review of water treatment membrane nanotechnologies. Energy Environ. Sci. 2011, 4, 1946-1971. [CrossRef]

10. Alsalhy, Q.F.; Ibrahim, S.S.; Khaleel, S.R. Performance of vacuum poly(propylene) membrane distillation (VMD) for saline water desalination. Chem. Eng. Process. Process. Intensif. 2017, 120, 68-80. [CrossRef]

11. Al-Ani, D.M.; Al-Ani, F.H.; Alsalhy, Q.F.; Ibrahim, S.S. Preparation and characterization of ultrafiltration membranes from PPSU-PES polymer blend for dye removal. Chem. Eng. Commun. 2019, 1-19. [CrossRef]

12. Alsalhy, Q.F.; Rashid, K.T.; Ibrahim, S.S.; Ghanim, A.H.; Bruggen, B.V.; Luis, P.; Zablouk, M. Poly(vinylidene fluoride-co-hexafluropropylene) (PVDF-co-HFP) hollow fiber membranes prepared from PVDF-co-HFP/PEG-600Mw/DMAC solution for membrane distillation. J. Appl. Polym. Sci. 2013, 129, 3304-3313. [CrossRef] 
13. Alsalhy, Q.F.; Al-Ani, F.H.; Al-Najar, A.E.; Jabuk, S.I. A study of the effect of embedding ZnO-NPs on PVC membrane performance use in actual hospital wastewater treatment by membrane bioreactor. Chem. Eng. Process. Process. Intensif. 2018, 130, 262-274. [CrossRef]

14. Alsalhy, Q.F.; Al-Ani, F.H.; Al-Najar, A.E. A new Sponge-GAC-Sponge membrane module for submerged membrane bioreactor use in hospital wastewater treatment. Biochem. Eng. J. 2018, 133, 130-139. [CrossRef]

15. Aljumaily, M.M.; Aljumaily, M.A.A.M.M.; Alsaadi, M.A.; Hashim, N.A.; Alsalhy, Q.F.; Das, R.; Mjalli, F.S. Embedded high-hydrophobic CNMs prepared by CVD technique with PVDF-co-HFP membrane for application in water desalination by DCMD. Desalin. Water Treat. 2019, 142, 37-48. [CrossRef]

16. Aljumaily, M.M.; Alsaadi, M.A.; Hashim, N.A.; Alsalhy, Q.F.; Mjalli, F.S.; Atieh, M.A.; Al-Harrasi, A. PVDF-co-HFP/superhydrophobic acetylene-based nanocarbon hybrid membrane for seawater desalination via DCMD. Chem. Eng. Res. Des. 2018, 138, 248-259. [CrossRef]

17. Jamed, M.J.; AlAnezi, A.A.; Alsalhy, Q.F. Effects of embedding functionalized multi-walled carbon nanotubes and alumina on the direct contact poly(vinylidene fluoride-co-hexafluoropropylene) membrane distillation performance. Chem. Eng. Commun. 2018, 206, 1035-1057. [CrossRef]

18. Sadiq, A.J.; Shabeeb, K.M.; Khalil, B.I.; Alsalhy, Q.F. Effect of embedding MWCNT-g-GO with PVC on the performance of PVC membranes for oily wastewater treatment. Chem. Eng. Commun. 2019, 207, 1-18. [CrossRef]

19. Al-Ani, F.H.; Alsalhy, Q.F.; Raheem, R.S.; Rashid, K.T.; Figoli, A. Experimental investigation of the effect of implanting tio2-nps on pvc for long-term uf membrane performance to treat refinery wastewater. Membranes 2020, 10, 77. [CrossRef]

20. Hussein, S.S.; Ibrahim, S.S.; Toma, M.A.; Alsalhy, Q.F.; Drioli, E. Novel chemical modification of polyvinyl chloride membrane by free radical graft copolymerization for direct contact membrane distillation (DCMD) application. J. Membr. Sci. 2020, 611, 118266. [CrossRef]

21. Geim, A.K.; Novoselov, K.S. The rise of graphene. Nat. Mater. 2007, 6, 183-191. [CrossRef] [PubMed]

22. Li, D.; Kaner, R.B. Materials Science: Graphene-Based Materials. Science 2008, 320, 1170-1171. [CrossRef] [PubMed]

23. Geim, A.K. Graphene: Status and Prospects. Science 2009, 324, 1530-1534. [CrossRef] [PubMed]

24. Huang, X.; Qi, X.; Boey, F.; Zhang, H. Graphene-based composites. Chem. Soc. Rev. 2012, 41, 666-686. [CrossRef]

25. Xu, Y.; Zhao, L.; Bai, H.; Hong, W.; Li, C.; Shi, G. Chemically Converted Graphene Induced Molecular Flattening of 5,10,15,20-Tetrakis(1-methyl-4-pyridinio)porphyrin and Its Application for Optical Detection of Cadmium(II) Ions. J. Am. Chem. Soc. 2009, 131, 13490-13497. [CrossRef] [PubMed]

26. Jin, F.; Lv, W.; Zhang, C.; Li, Z.; Su, R.; Qi, W.; Yang, Q.-H.; He, Z. High-performance ultrafiltration membranes based on polyethersulfone-graphene oxide composites. RSC Adv. 2013, 3, 21394-21397. [CrossRef]

27. Sabri, A.; Marino, T.; Parsa, J.B.; Galiano, F.; Ursino, C.; Garcìa, H.; Puche, M.; Figoli, A. Polyvinylidene Fluoride-Graphene Oxide Membranes for Dye Removal under Visible Light Irradiation. Polymers 2020, 12, 1509. [CrossRef]

28. Junaidi, N.F.; Khalil, N.A.; Jahari, A.F.; Shaari, N.Z.; Shahruddin, M.Z.; Alias, N.H.; Othman, N.H. Effect of Graphene Oxide (GO) on the Surface Morphology \& Hydrophilicity of Polyethersulfone (PES). Mater. Sci. Eng. 2018, 358, 012047. [CrossRef]

29. Mahmoud, K.A.; Mansoor, B.; Mansour, A.; Khraisheh, M. Functional graphene nanosheets: The next generation membranes for water desalination. Desalination 2015, 356, 208-225. [CrossRef]

30. Zinadini, S.; Zinatizadeh, A.A.; Rahimi, M.; Vatanpour, V.; Zangeneh, H. Preparation of a novel antifouling mixed matrix PES membrane by embedding graphene oxide nanoplates. J. Membr. Sci. 2014, 453, $292-301$. [CrossRef]

31. Wang, Z.; Yu, H.; Xia, J.; Zhang, F.; Li, F.; Xia, Y.; Li, Y. Novel GO-blended PVDF ultrafiltration membranes. Desalination 2012, 299, 50-54. [CrossRef]

32. Makhetha, T.; Moutloali, R. Antifouling properties of $\mathrm{Cu}(\mathrm{tpa}) @ \mathrm{GO} / \mathrm{PES}$ composite membranes and selective dye rejection. J. Membr. Sci. 2018, 554, 195-210. [CrossRef]

33. Gholami, N.; Mahdavi, H. Nanofiltration composite membranes of polyethersulfone and graphene oxide and sulfonated graphene oxide. Adv. Polym. Technol. 2018, 37, 3529-3541. [CrossRef]

34. Abdelkarim, A.A.; Leaper, S.; Alberto, M.; Vijayaraghavan, A.; Fan, X.; Holmes, S.M.; Souaya, E.R.; Badawy, M.I.; Gorgojo, P. High flux and fouling resistant flat sheet polyethersulfone membranes incorporated with graphene oxide for ultrafiltration applications. Chem. Eng. J. 2018, 334, 789-799. [CrossRef] 
35. Wang, X.; Feng, M.; Liu, Y.; Deng, H.; Lu, J. Fabrication of graphene oxide blended polyethersulfone membranes via phase inversion assisted by electric field for improved separation and antifouling performance. J. Membr. Sci. 2019, 577, 41-50. [CrossRef]

36. Luque-Alled, J.M.; Abdel-Karim, A.; Alberto, M.; Leaper, S.; Perez-Page, M.; Huang, K.; Vijayaraghavan, A.; El-Kalliny, A.S.; Holmes, S.M.; Gorgojo, P. Polyethersulfone membranes: From ultrafiltration to nanofiltration via the incorporation of APTS functionalized-graphene oxide. Sep. Purif. Technol. 2020, 230, 230. [CrossRef]

37. Kumar, M.; McGlade, D.; Ulbricht, M.; Lawler, J. Quaternized polysulfone and graphene oxide nanosheet derived low fouling novel positively charged hybrid ultrafiltration membranes for protein separation. RSC Adv. 2015, 5, 51208-51219. [CrossRef]

38. Akbari, M.; Shariaty-Niassar, M.; Matsuura, T.; Ismail, A.F. Janus graphene oxide nanosheet: A promising additive for enhancement of polymeric membranes performance prepared via phase inversion. J. Colloid Interface Sci. 2018, 527, 10-24. [CrossRef]

39. Xu, Z.; Zhang, J.; Shan, M.; Li, Y.; Li, B.; Niu, J.; Zhou, B.; Qian, X. Organosilane-functionalized graphene oxide for enhanced antifouling and mechanical properties of polyvinylidene fluoride ultrafiltration membranes. J. Membr. Sci. 2014, 458, 1-13. [CrossRef]

40. Zhao, C.; Xu, X.; Chen, J.; Wang, G.; Yang, F. Highly effective antifouling performance of PVDF/graphene oxide composite membrane in membrane bioreactor (MBR) system. Desalination 2014, 340, 59-66. [CrossRef]

41. Esfahani, M.R.; Tyler, J.L.; Stretz, H.A.; Wells, M.J. Effects of a dual nanofiller, nano-TiO2 and MWCNT, for polysulfone-based nanocomposite membranes for water purification. Desalination 2015, 372, 47-56. [CrossRef]

42. Galiano, F.; Ghanim, A.H.; Rashid, K.T.; Marino, T.; Simone, S.; Alsalhy, Q.F.; Figoli, A. Preparation and characterization of green polylactic acid (PLA) membranes for organic/organic separation by pervaporation. Clean Technol. Environ. Policy 2019, 21, 109-120. [CrossRef]

43. Ismael, A.E. Nano Submerged Membrane Bioreactor for Hospital Wastewater Treatment; University of Technology: Baghdad, Iraq, 2017.

44. Vatanpour, V.; Esmaeili, M.; Farahani, M.H.D.A. Fouling reduction and retention increment of polyethersulfone nanofiltration membranes embedded by amine-functionalized multi-walled carbon nanotubes. J. Membr. Sci. 2014, 466, 70-81. [CrossRef]

45. Vatanpour, V.; Madaeni, S.; Moradian, R.; Zinadini, S.; Astinchap, B. Fabrication and characterization of novel antifouling nanofiltration membrane prepared from oxidized multiwalled carbon nanotube/polyethersulfone nanocomposite. J. Membr. Sci. 2011, 375, 284-294. [CrossRef]

46. Mahmoodi, N.M.; Ghezelbash, M.; Shabanian, M.; Aryanasab, F.; Saeb, M.R. Efficient removal of cationic dyes from colored wastewaters by dithiocarbamate-functionalized graphene oxide nanosheets: From synthesis to detailed kinetics studies. J. Taiwan Inst. Chem. Eng. 2017, 81, 239-246. [CrossRef]

47. Safarpour, M.; Vatanpour, V.; Khataee, A. Preparation and characterization of graphene oxide/TiO 2 blended PES nanofiltration membrane with improved antifouling and separation performance. Desalination 2016, 393, 65-78. [CrossRef]

48. Sun, M.; Su, Y.; Mu, C.; Jiang, Z. Improved Antifouling Property of PES Ultrafiltration Membranes Using Additive of Silica-PVP Nanocomposite. Ind. Eng. Chem. Res. 2010, 49, 790-796. [CrossRef]

49. Ganesh, B.M.; Isloor, A.M.; Ismail, A.F. Enhanced hydrophilicity and salt rejection study of graphene oxide-polysulfone mixed matrix membrane. Desalination 2013, 313, 199-207. [CrossRef]

50. Vatanpour, V.; Madaeni, S.S.; Moradian, R.; Zinadini, S.; Astinchap, B. Novel antibifouling nanofiltration polyethersulfone membrane fabricated from embedding $\mathrm{TiO}_{2}$ coated multiwalled carbon nanotubes. Sep. Purif. Technol. 2012, 90, 69-82. [CrossRef]

51. Rezaee, R.; Nasseri, S.; Mahvi, A.H.; Nabizadeh, R.; Mousavi, S.A.; Rashidi, A.; Jafari, A.; Nazmara, S. Fabrication and characterization of a polysulfone-graphene oxide nanocomposite membrane for arsenate rejection from water. J. Environ. Heal. Sci. Eng. 2015, 13, 1-11. [CrossRef]

52. Vatanpour, V.; Madaeni, S.S.; Khataee, A.R.; Salehi, E.; Zinadini, S.; Monfared, H.A. TiO 2 embedded mixed matrix PES nanocomposite membranes: Influence of different sizes and types of nanoparticles on antifouling and performance. Desalination 2012, 292, 19-29. [CrossRef]

53. Qiu, S.; Wu, L.; Pan, X.; Zhang, L.; Chen, H.; Gao, C. Preparation and properties of functionalized carbon nanotube/PSF blend ultrafiltration membranes. J. Membr. Sci. 2009, 342, 165-172. [CrossRef]

54. Lohokare, H.; Muthu, M.; Agarwal, G.; Kharul, U.K. Effective arsenic removal using polyacrylonitrile-based ultrafiltration (UF) membrane. J. Membr. Sci. 2008, 320, 159-166. [CrossRef] 
55. Xia, S.; Yao, L.; Zhao, Y.; Li, N.; Zheng, Y. Preparation of graphene oxide modified polyamide thin film composite membranes with improved hydrophilicity for natural organic matter removal. Chem. Eng. J. 2015, 280, 720-727. [CrossRef]

56. Thomas, T.E.; Al Aani, S.; Oatley-Radcliffe, D.L.; Williams, P.M.; Hilal, N. Laser Doppler Electrophoresis and electro-osmotic flow mapping: A novel methodology for the determination of membrane surface zeta potential. J. Membr. Sci. 2017, 523, 524-532. [CrossRef]

57. Boukoussa, B.; Hamacha, R.; Morsli, A.; Bengueddach, A. Adsorption of yellow dye on calcined or uncalcined Al-MCM-41 mesoporous materials. Arab. J. Chem. 2017, 10, S2160-S2169. [CrossRef]

58. Van Der Bruggen, B.; Vandecasteele, C.; Van Gestel, T.; Doyen, W.; Leysen, R. A review of pressure-driven membrane processes in wastewater treatment and drinking water production. Environ. Prog. 2003, 22, 46-56. [CrossRef]

59. Lau, W.; Ismail, A.F. Application of response surface methodology in pes/speek blend NF membrane for dyeing solution treatment. Membr. Water Treat. 2010, 1, 49-60. [CrossRef]

Publisher's Note: MDPI stays neutral with regard to jurisdictional claims in published maps and institutional affiliations.

(C) 2020 by the authors. Licensee MDPI, Basel, Switzerland. This article is an open access article distributed under the terms and conditions of the Creative Commons Attribution (CC BY) license (http://creativecommons.org/licenses/by/4.0/). 